SUPPORTING INFORMATION

\title{
Common Strategy for the Synthesis of Some Strychnos Indole Alkaloids
}

Gaetan Maertens, Elsa Deruer, Maxime Denis and Sylvain Canesi*

Laboratoire de Méthodologie et Synthèse de Produit Naturels

Université du Québec à Montréal, C.P.8888, Succ. Centre-Ville,

Montréal. H3C 3P8, Québec, Canada.

*E-mail: canesi.sylvain@uqam.ca; Fax: (+1) 514-987-4054

Table of contents

I. Circular dichroism spectroscopy of (-)-strychnopivotine S2

II. X-Ray crystal structure analysis of $16 \quad$ S3

III. Copies of ${ }^{1} \mathrm{H}$ and ${ }^{13} \mathrm{C}$ NMR spectra $\quad$ S5 


\section{Circular dichroism spectroscopy of (-)-Strychnopivotine}

Circular dichroism experiments were carried out on a Jasco J-815 spectropolarimeter at $25^{\circ} \mathrm{C}$ in a $0.0019 \mathrm{M}$ methanol solution at $1.0 \mathrm{~mm}$ pathlength. Spectra were corrected from a baseline (pure solvent) that was collected the same number of times as the spectra.

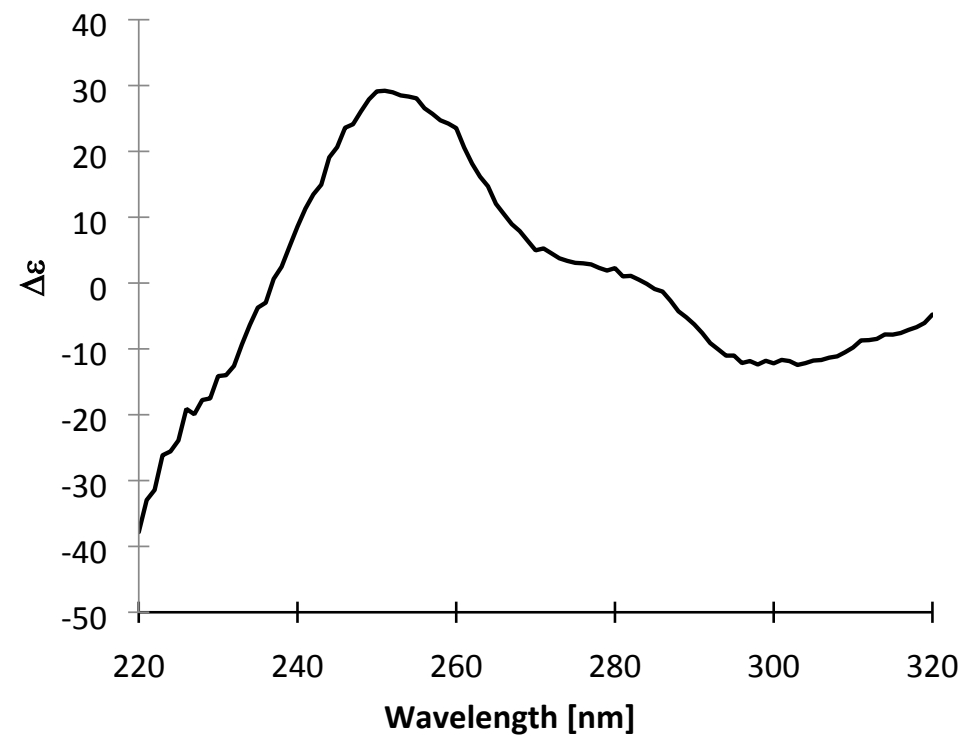

Figure S1. CD spectrum of (-)-Strychnopivotine $(c=0.0019 \mathrm{M}$ in $\mathrm{MeOH})$. 


\section{X-Ray crystal structure analysis of 16}

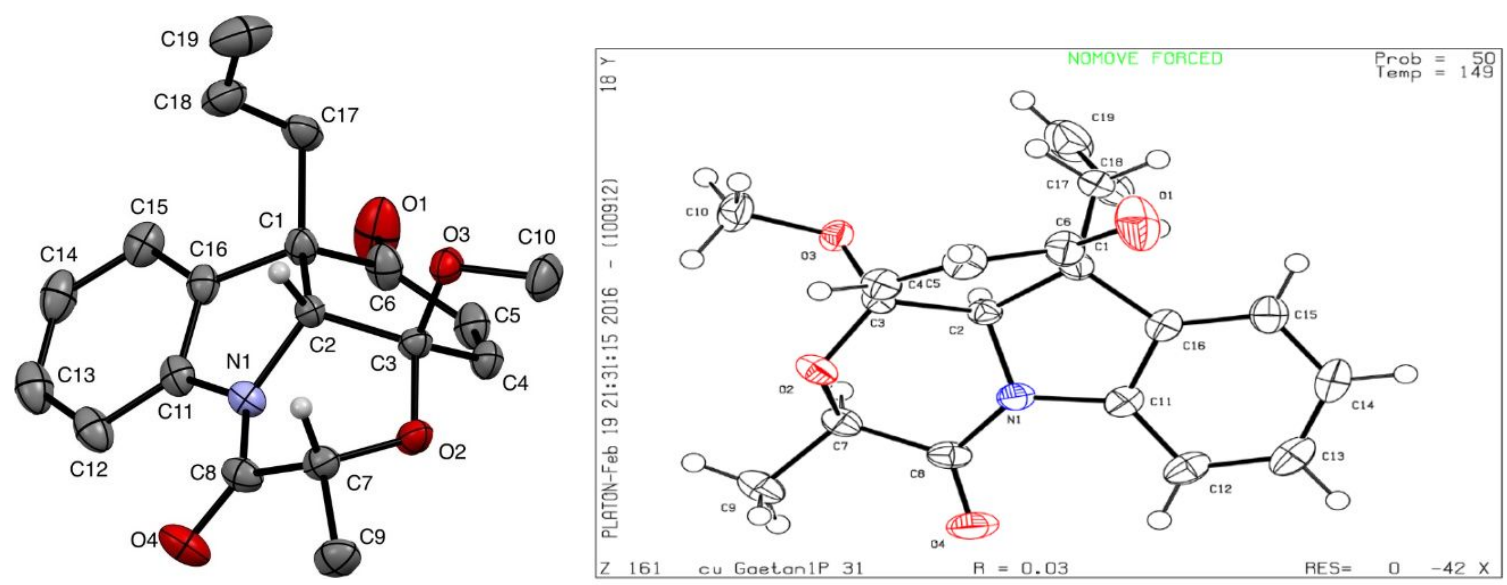

Figure S2. ORTEP representation at $50 \%$ ellipsoid probability of 16 . Hydrogen atoms were omitted for clarity, except on asymmetric carbon atoms (C2 and C7).

Crystals were directly obtained after silica gel chromatography (15:85 EtOAc/n-Hex), a recrystallization can be promoted in presence of methanol if necessary.

Crystallographic analysis was performed on a Bruker APEX-DUO diffractometer. A colorless needle-like specimen of $\mathrm{C}_{19} \mathrm{H}_{19} \mathrm{NO}_{4}$, approximate dimensions $0.155 \mathrm{~mm} \times 0.161$ $\mathrm{mm} \times 0.359 \mathrm{~mm}$, was used for the X-ray crystallographic analysis. The X-ray intensity data were measured. A total of 5856 frames were collected. The total exposure time was 10.98 hours. The frames were integrated with the Bruker SAINT software package using a narrow-frame algorithm. The integration of the data using a trigonal unit cell yielded a total of 18370 reflections to a maximum $\theta$ angle of $68.27^{\circ}$ (0.83 $\AA$ resolution), of which 3007 were independent (average redundancy 6.109 , completeness $=100.0 \%, R_{\text {int }}=7.34 \%, R_{\text {sig }}$ $=4.61 \%)$ and $2906(96.64 \%)$ were greater than $2 \sigma\left(\mathrm{F}^{2}\right)$. The final cell constants of $a=b=$ $8.6520(2) \AA, c=19.0082(6) \AA$, volume $=1232.27(7) \AA^{3}$, are based upon the refinement of the $\mathrm{XYZ}$-centroids of 6230 reflections above $20 \sigma(\mathrm{I})$ with $11.81^{\circ}<2 \theta<136.5^{\circ}$. Data were corrected for absorption effects using the multi-scan method (SADABS). The ratio of minimum to maximum apparent transmission was 0.891 . The calculated minimum and maximum transmission coefficients (based on crystal size) are 0.6560 and 0.7360 .

The structure was solved and refined using the Bruker SHELXTL Software Package, using the space group $\mathrm{P} 3_{1}$, with $\mathrm{Z}=3$ for the formula unit, $\mathrm{C}_{19} \mathrm{H}_{19} \mathrm{NO}_{4}$. The final anisotropic fullmatrix least-squares refinement on $F^{2}$ with 220 variables converged at $R_{1}=3.19 \%$, for the observed data and $w R_{2}=8.07 \%$ for all data. The goodness-of-fit was 1.049 . The largest peak in the final difference electron density synthesis was $0.189 \mathrm{e} / \AA^{3}$ and the largest hole was $-0.126 \mathrm{e}-/ \AA^{3}$ with an RMS deviation of $0.035 \mathrm{e}^{-} / \AA^{3}$. On the basis of the final model, the calculated density was $1.315 \mathrm{~g} / \mathrm{cm}^{3}$ and $F(000), 516 \mathrm{e}^{-}$.

The absolute structure was assigned using $\mathrm{C} 7$, which $R$ configuration remains intact during synthesis. In addition, absolute structure was also determined using anomalous scatterers, which led to a Flack parameter of $0.16(12)$. Despite the large uncertainty due 
to the lack of heavy atoms, this value is sufficient close to zero to corroborate the absolute structure assignment.

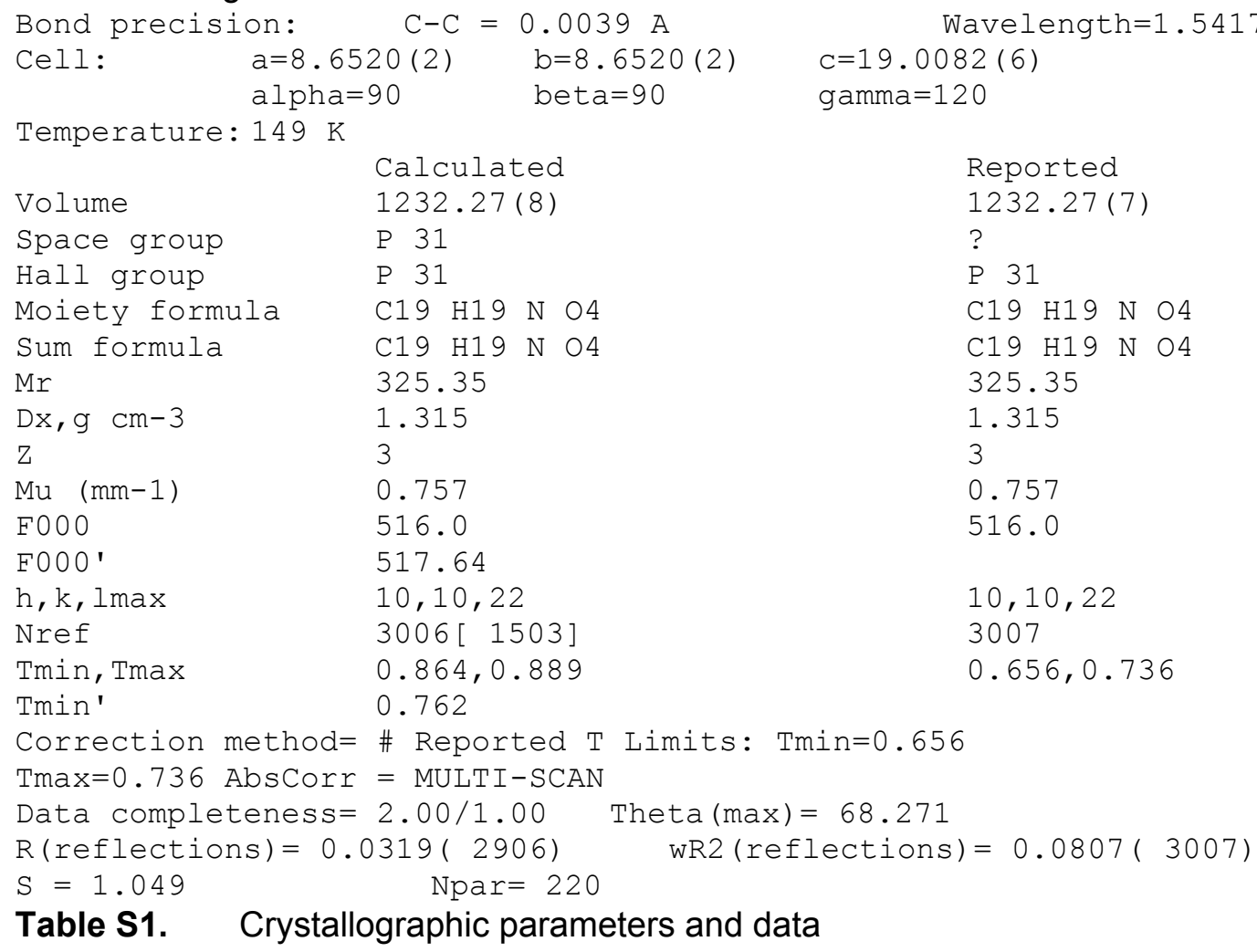

Table S1. Crystallographic parameters and data

Crystallographic parameters and data are provided in the CIF file which can be retrieved from the Cambridge Crystallographic Data Centre using deposition number 1454833 at the following URL:

http://www.ccdc.cam.ac.uk/Community/Requestastructure/Pages/Requestastructure.asp $\mathrm{x}$ 


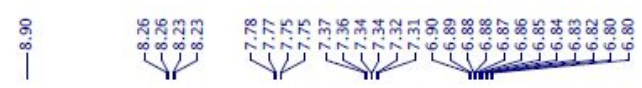

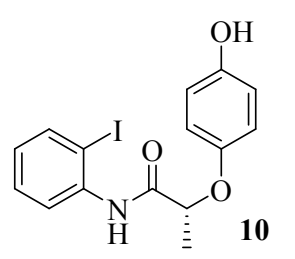

$300 \mathrm{MHz}, \mathrm{CDCl}_{3}$

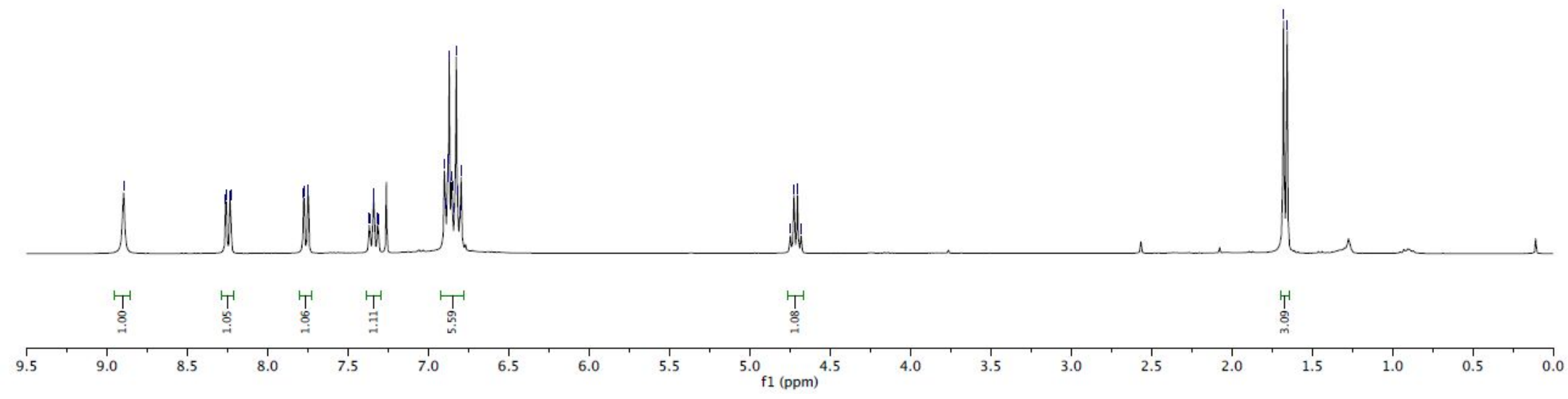




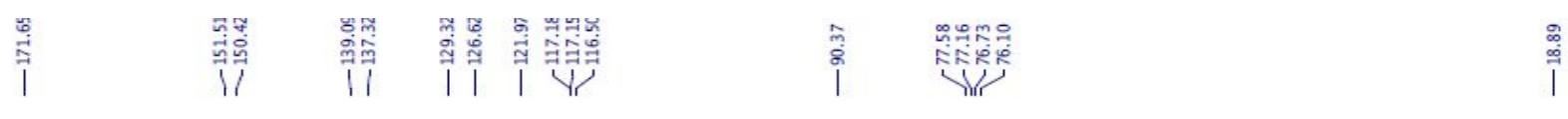

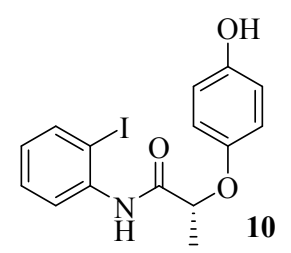

$75 \mathrm{MHz}, \mathrm{CDCl}_{3}$

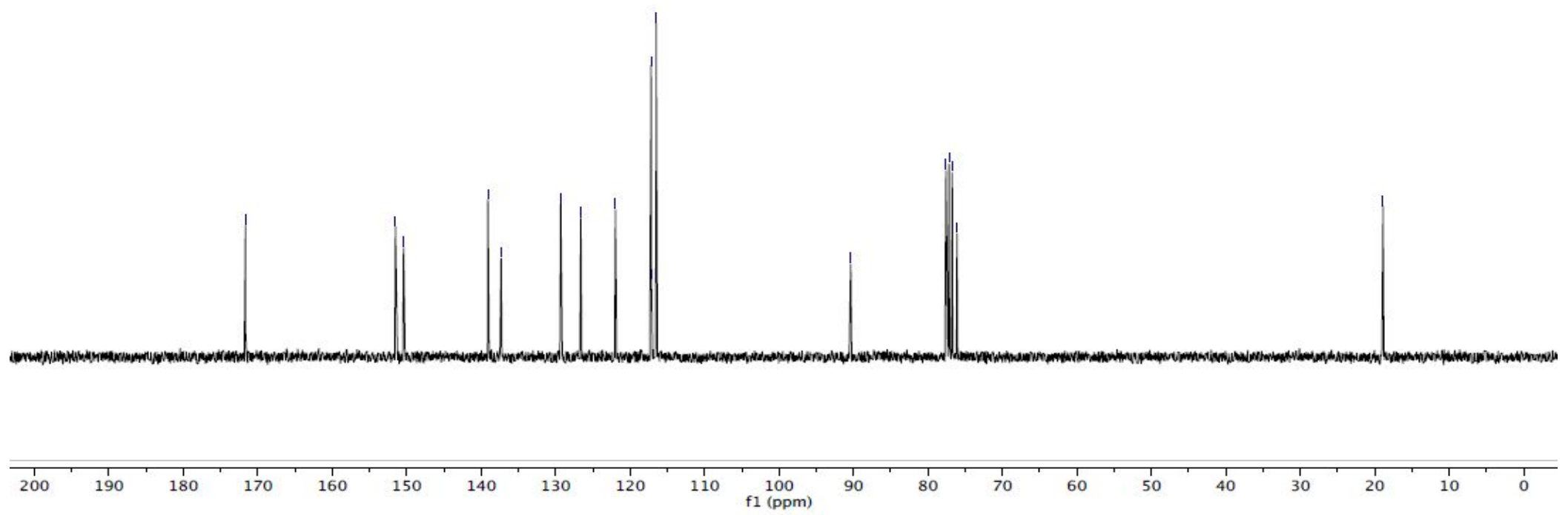




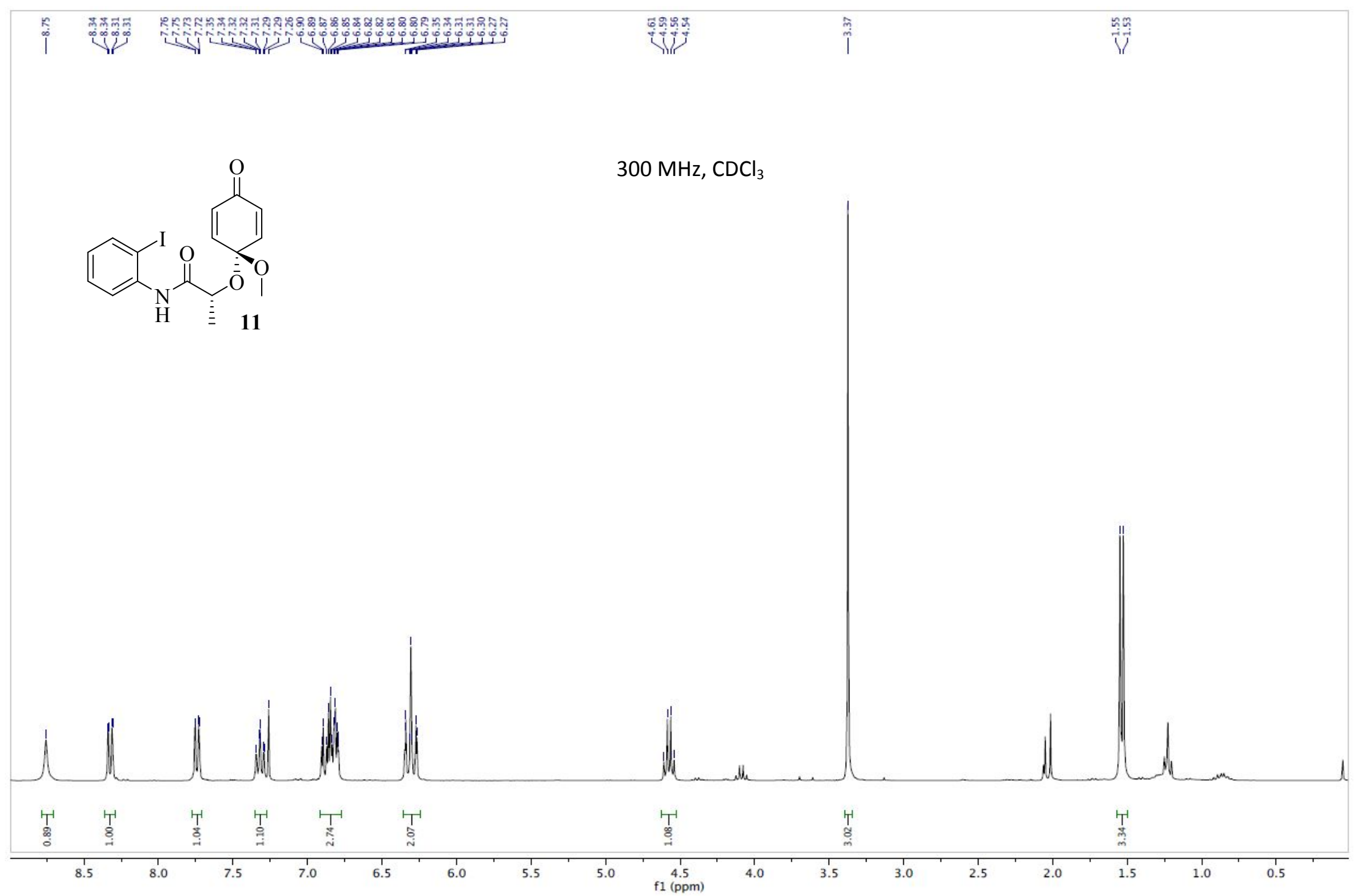




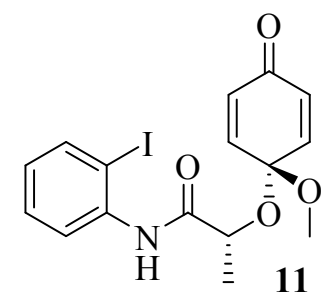

$75 \mathrm{MHz}, \mathrm{CDCl}_{3}$

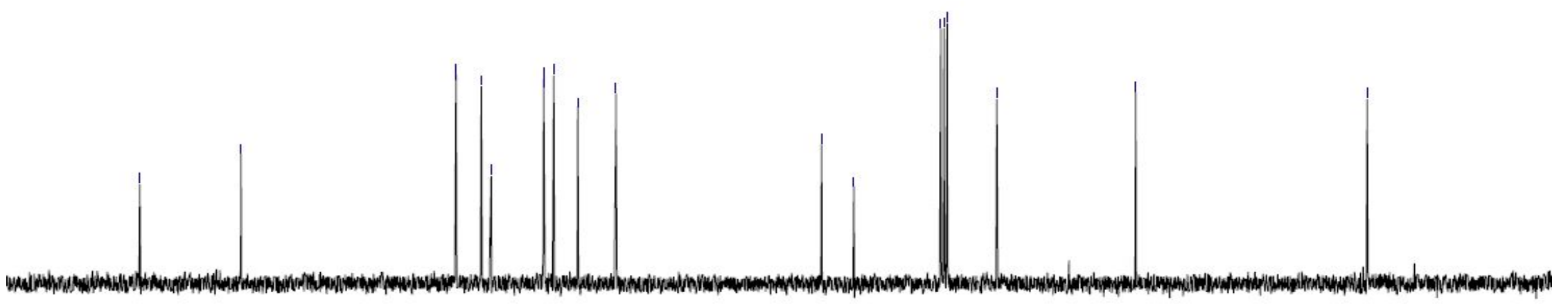




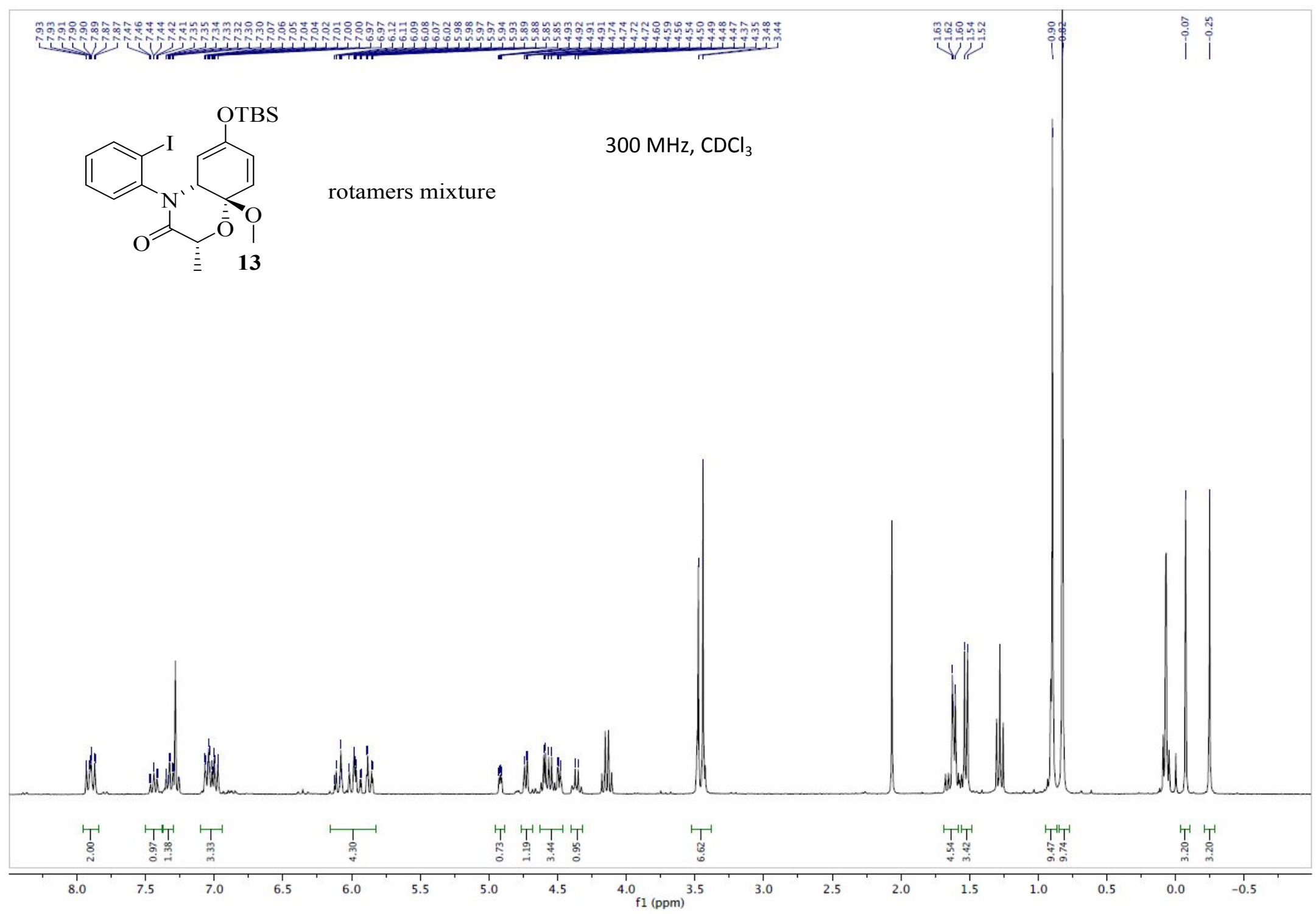




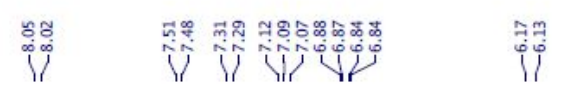

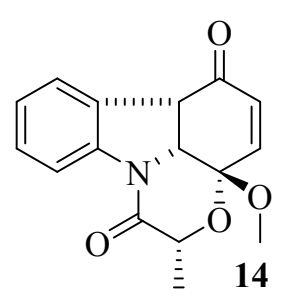

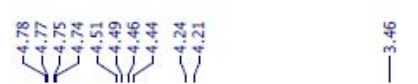

$300 \mathrm{MHz}, \mathrm{CDCl}_{3}$

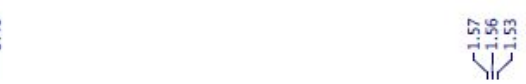

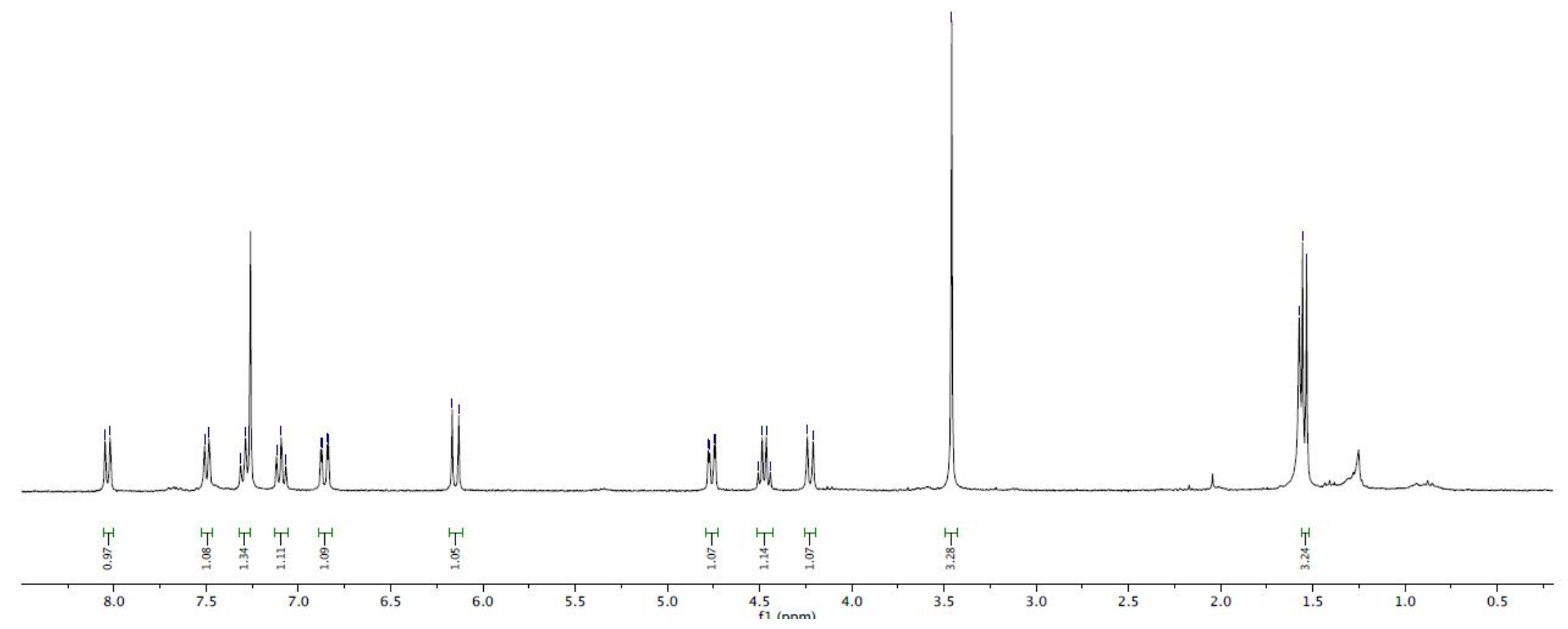




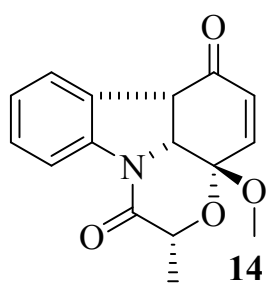

$75 \mathrm{MHz}_{2} \mathrm{CDCl}_{3}$

1.

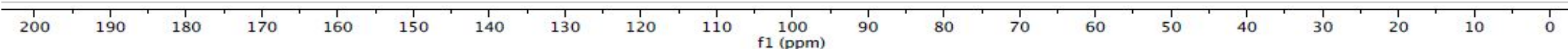




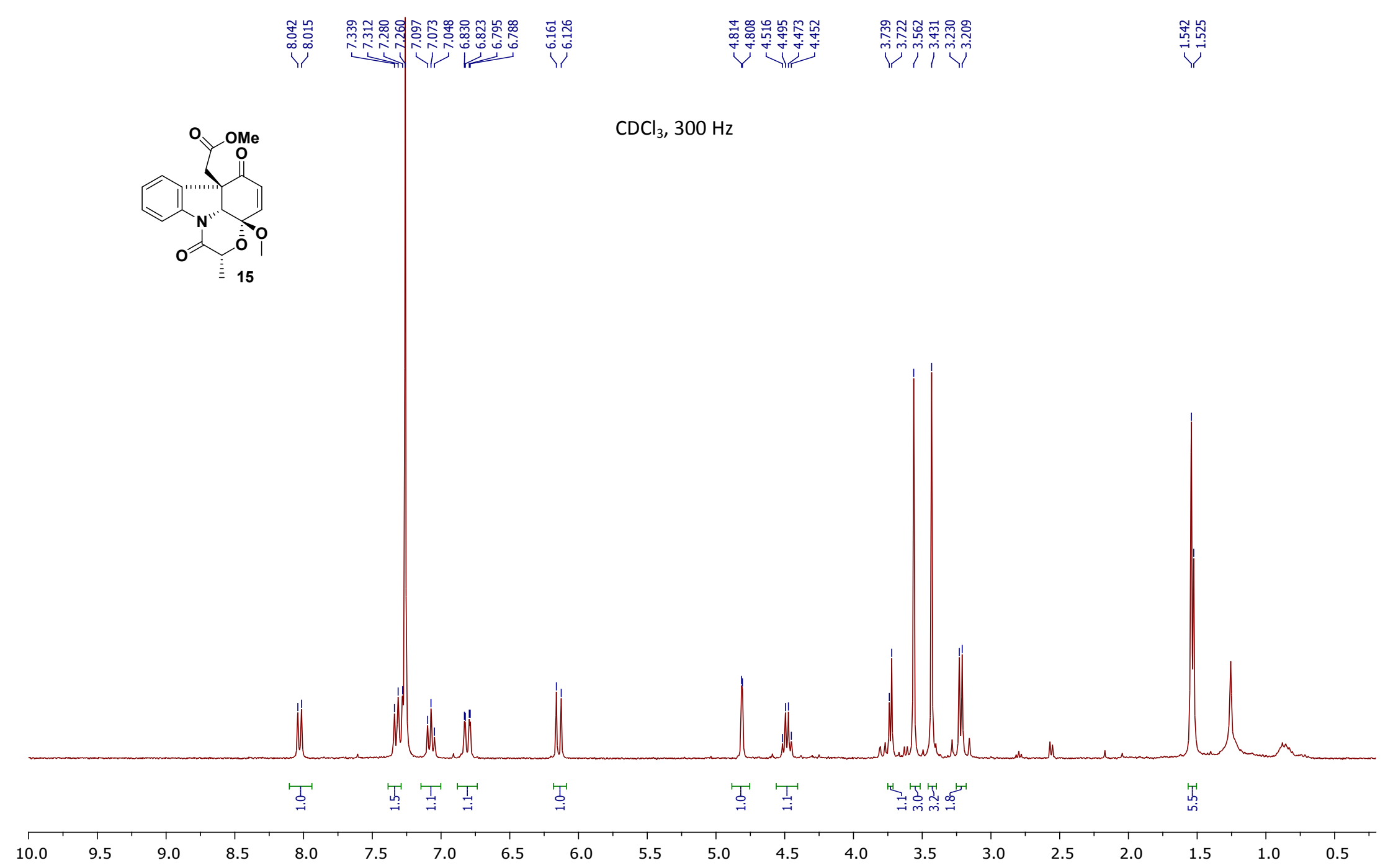




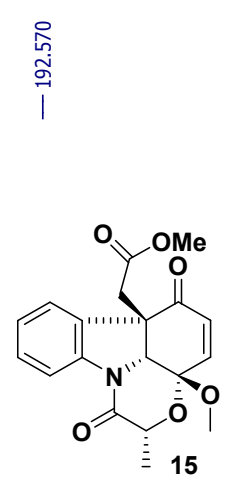

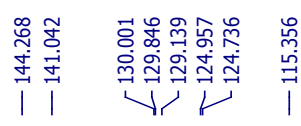

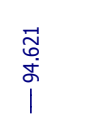

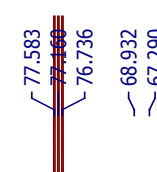

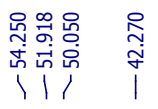

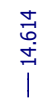

$\mathrm{CDCl}_{3}, 75 \mathrm{MHz}$

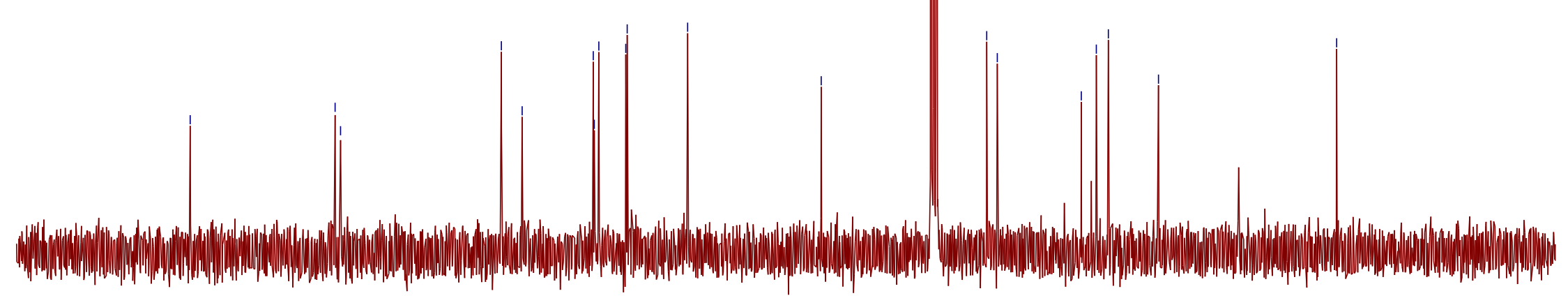

$\begin{array}{llllllllllll}210 & 200 & 190 & 180 & 170 & 160 & 150 & 140 & 130 & 120 & 110 & 100\end{array}$

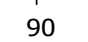

$80 \quad 70$

60

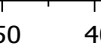

1
30

20 


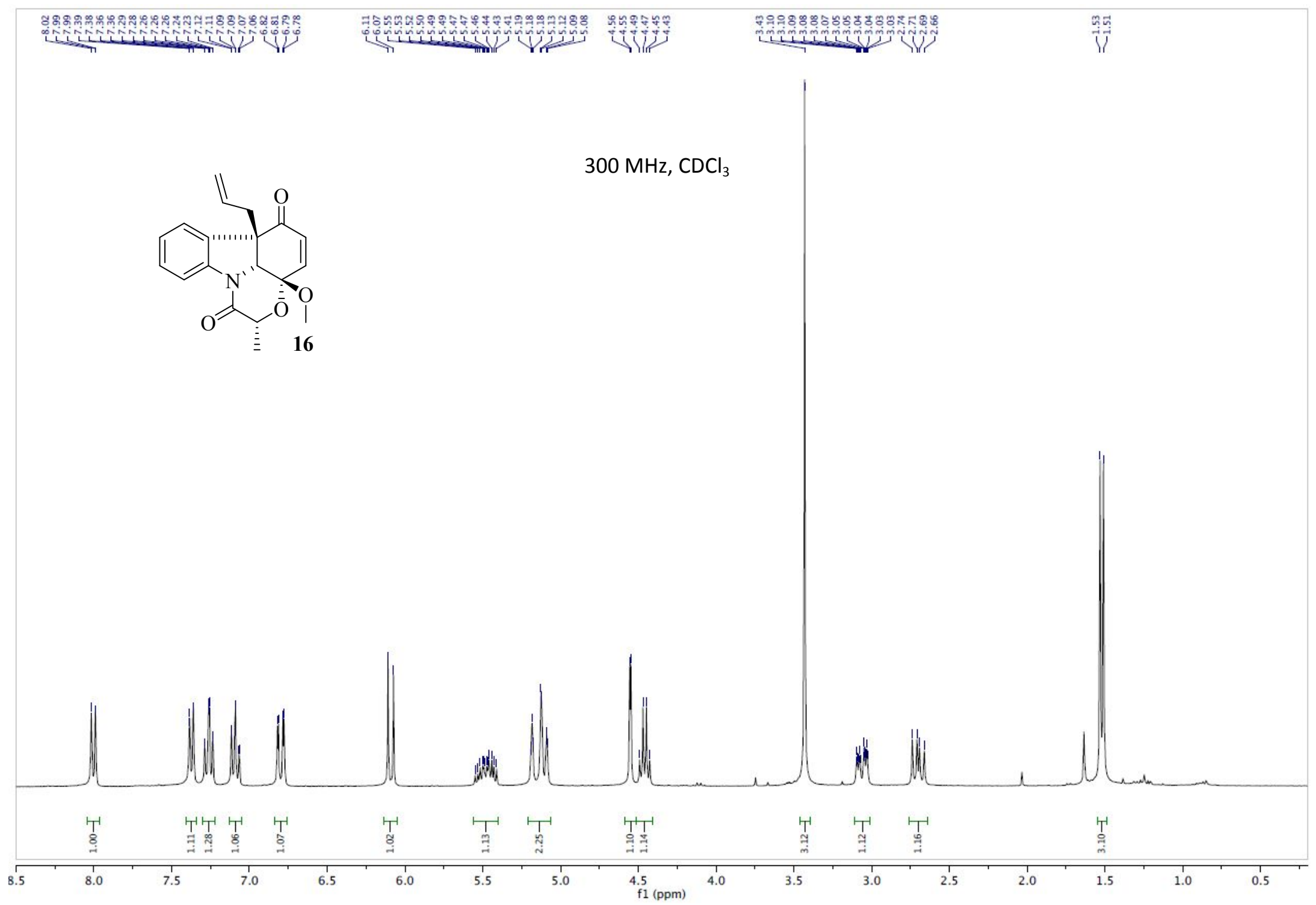

S14 


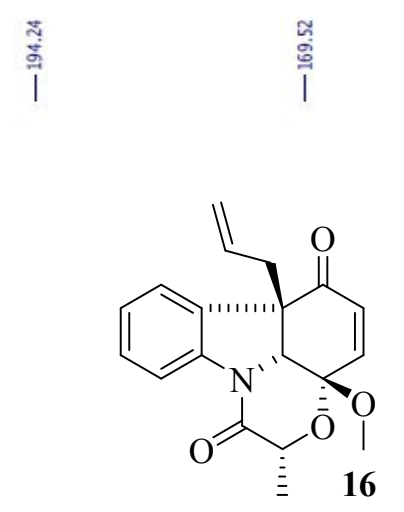

$75 \mathrm{MHz}, \mathrm{CDCl}_{3}$

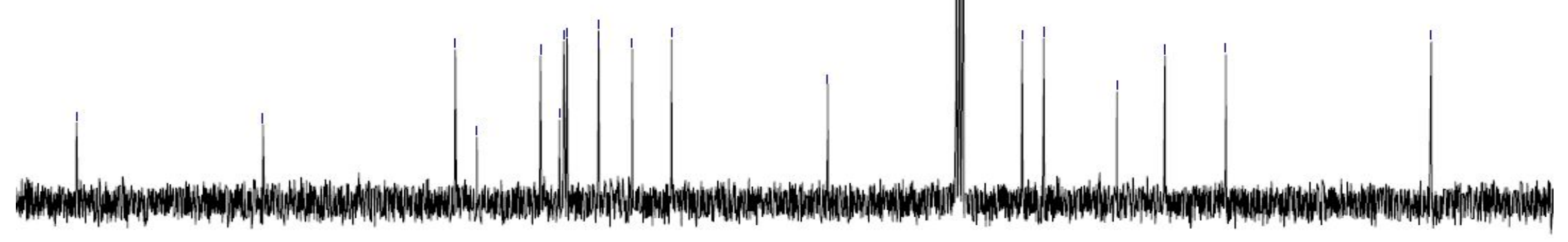

200 190 $1 8 0 \longdiv { 1 7 0 }$ 160 $150 \quad 140$ 130 120 $110 \quad \begin{gathered}100 \\ \text { f1 }(\mathrm{ppm})\end{gathered}$ 90 80 70 60 


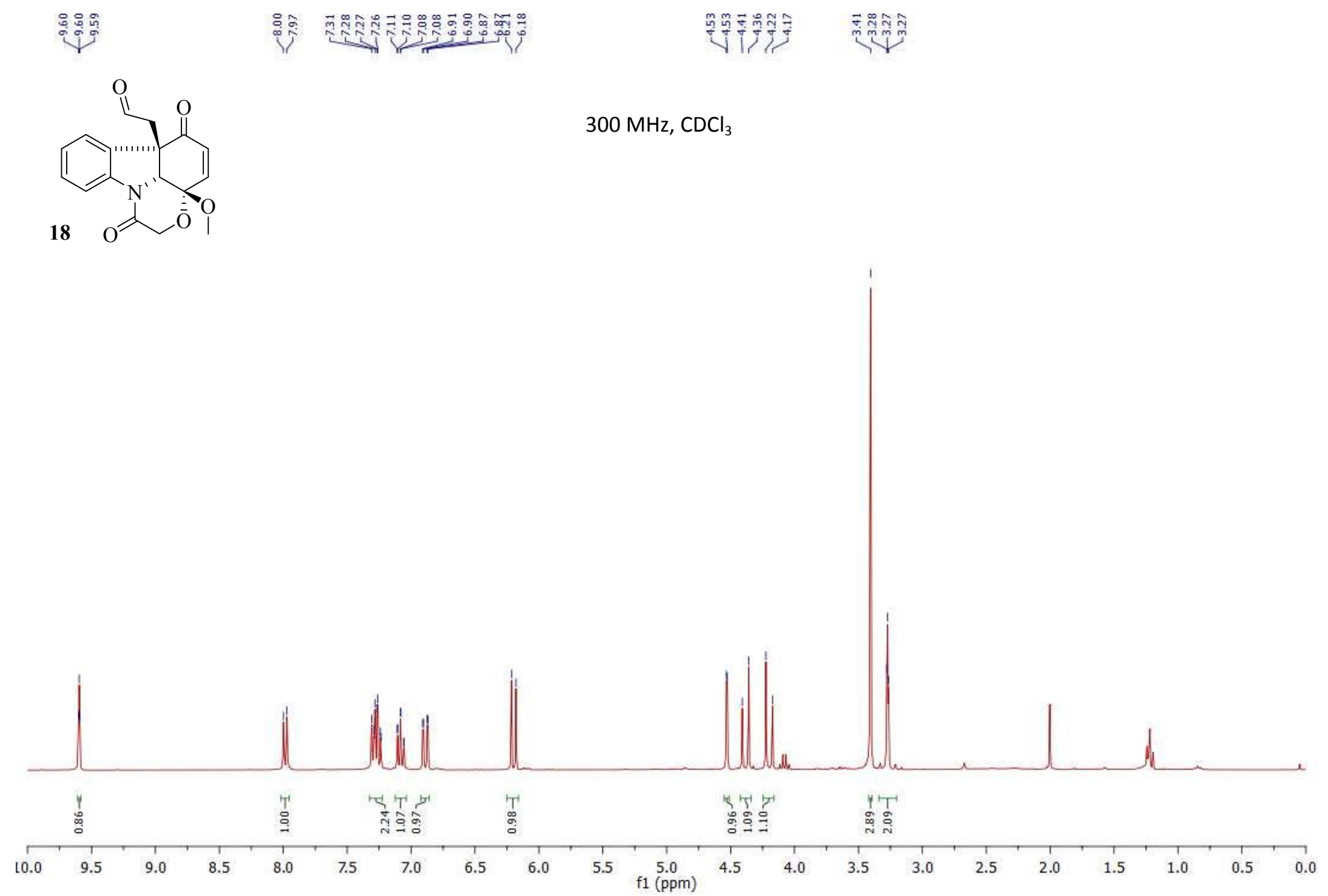



†े

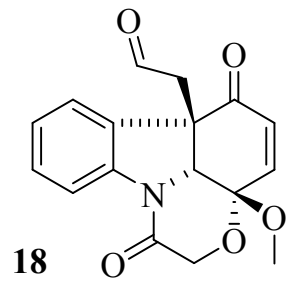

$75 \mathrm{MHz}, \mathrm{CDCl}_{3}$

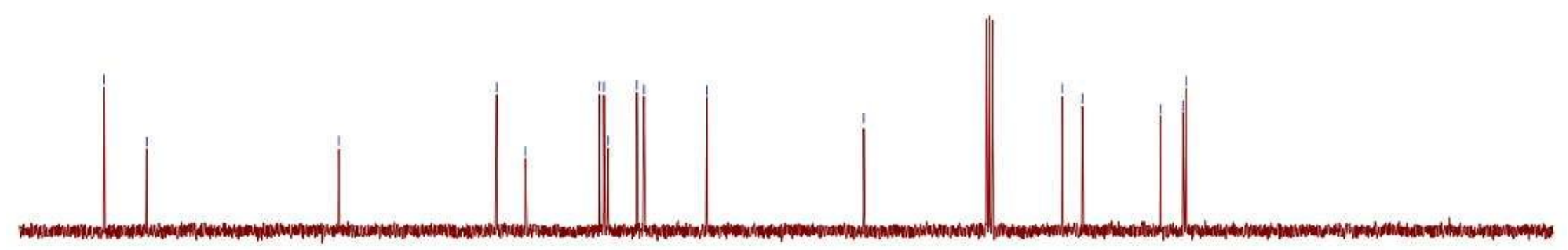




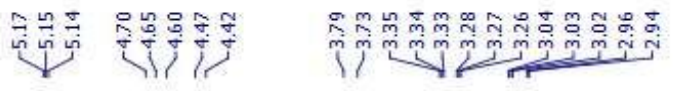

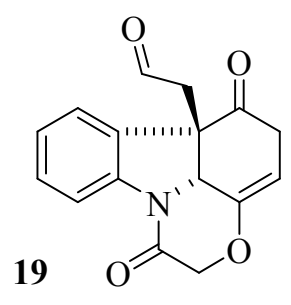

$300 \mathrm{MHz}, \mathrm{CDCl}_{3}$

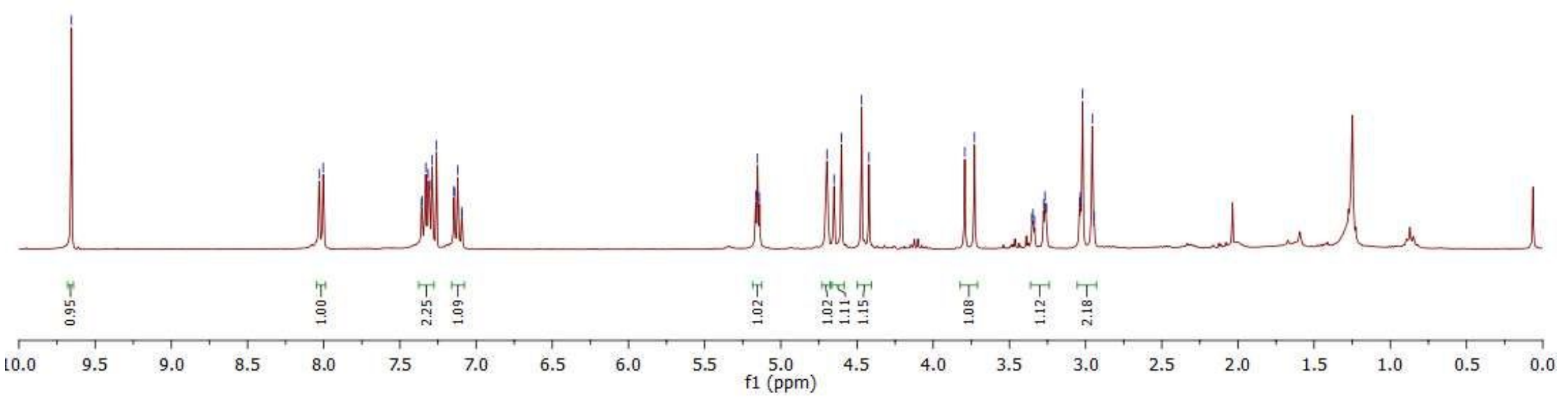



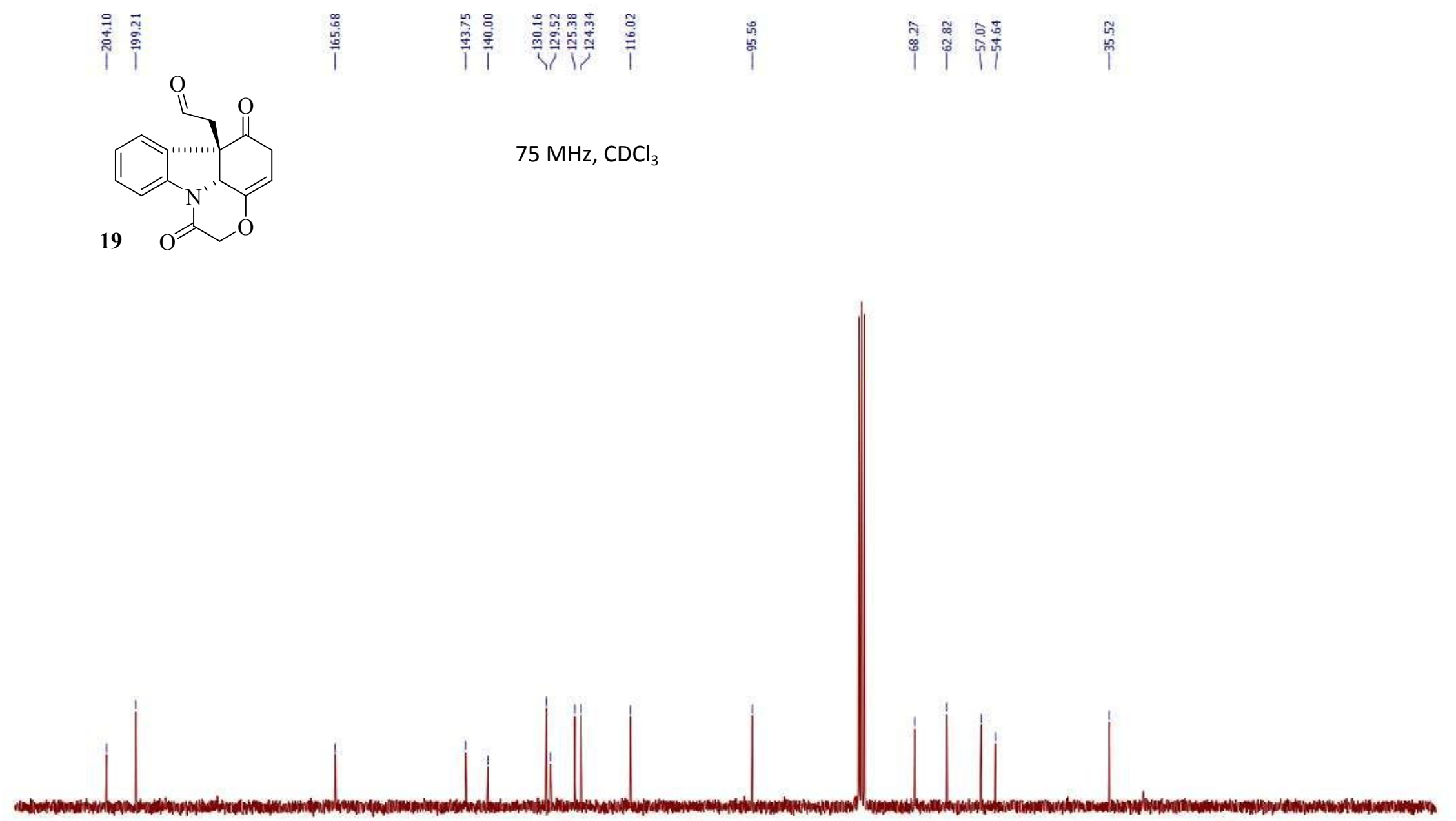

$210 \quad 200 \quad 190 \quad 180$

$170 \quad 160$

140

$130 \quad 120$

$110 \quad 100$

80

$\begin{array}{ccc}1 & 1 & 1 \\ 70 & 60 & 50\end{array}$

$40 \quad 30$

20

10

1
-10 


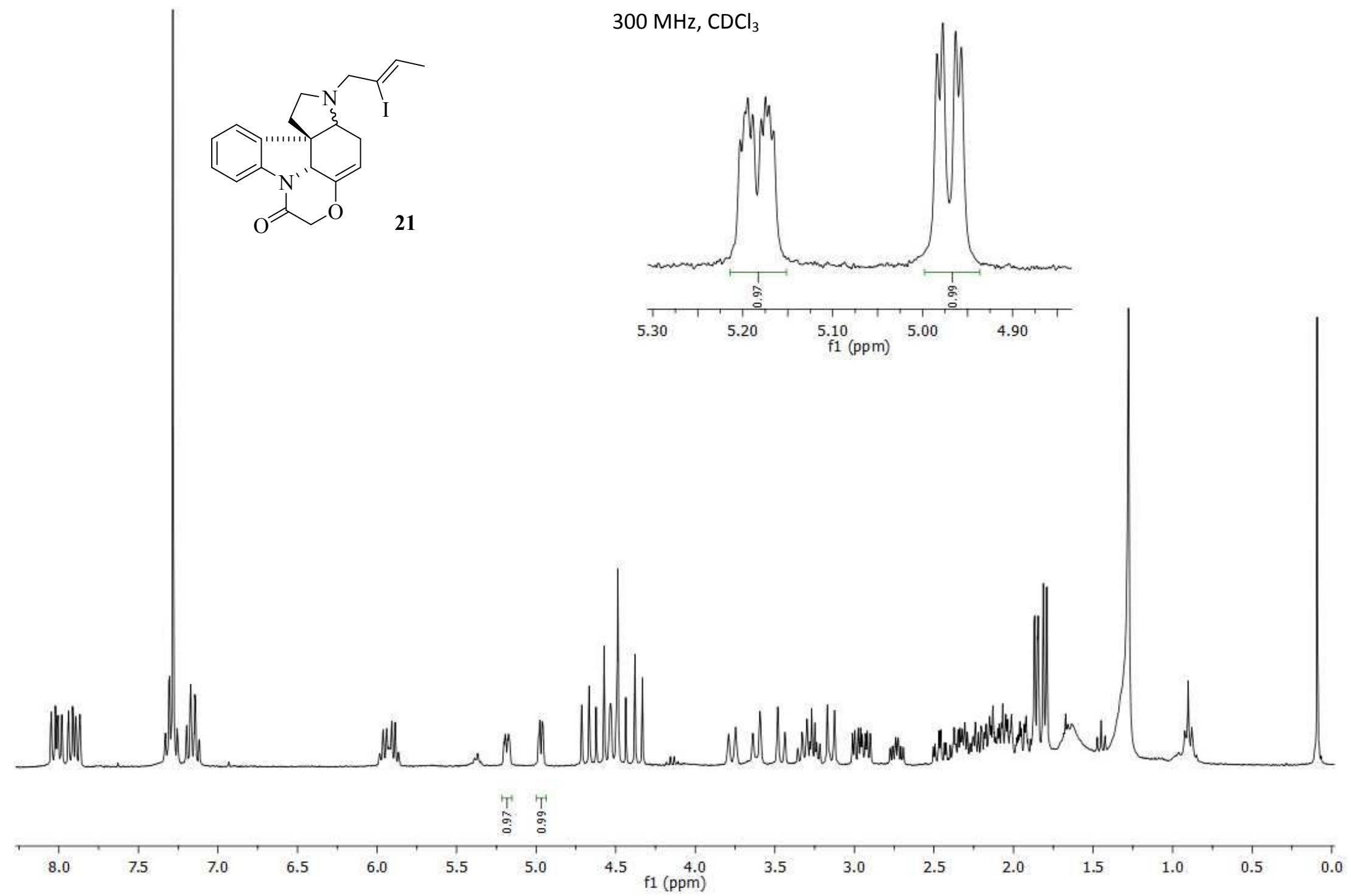




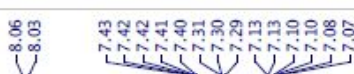

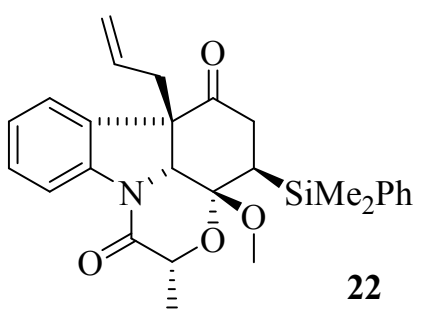

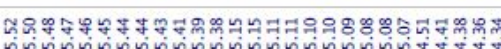

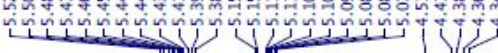

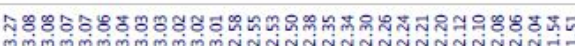

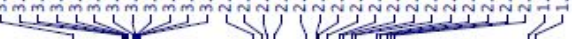

$300 \mathrm{MHz}, \mathrm{CDCl}_{3}$

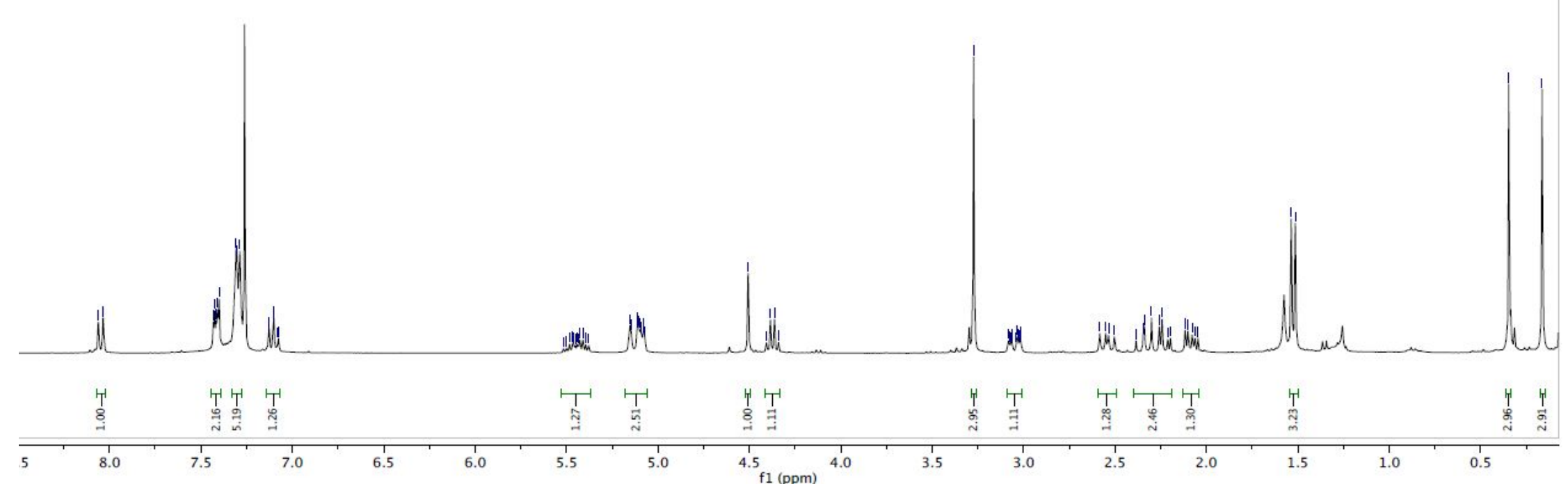




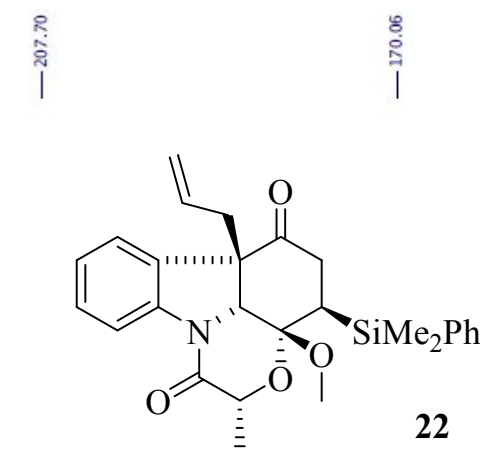

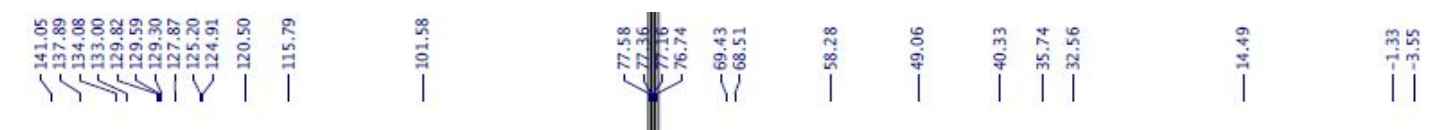

$75 \mathrm{MHz}, \mathrm{CDCl}_{3}$
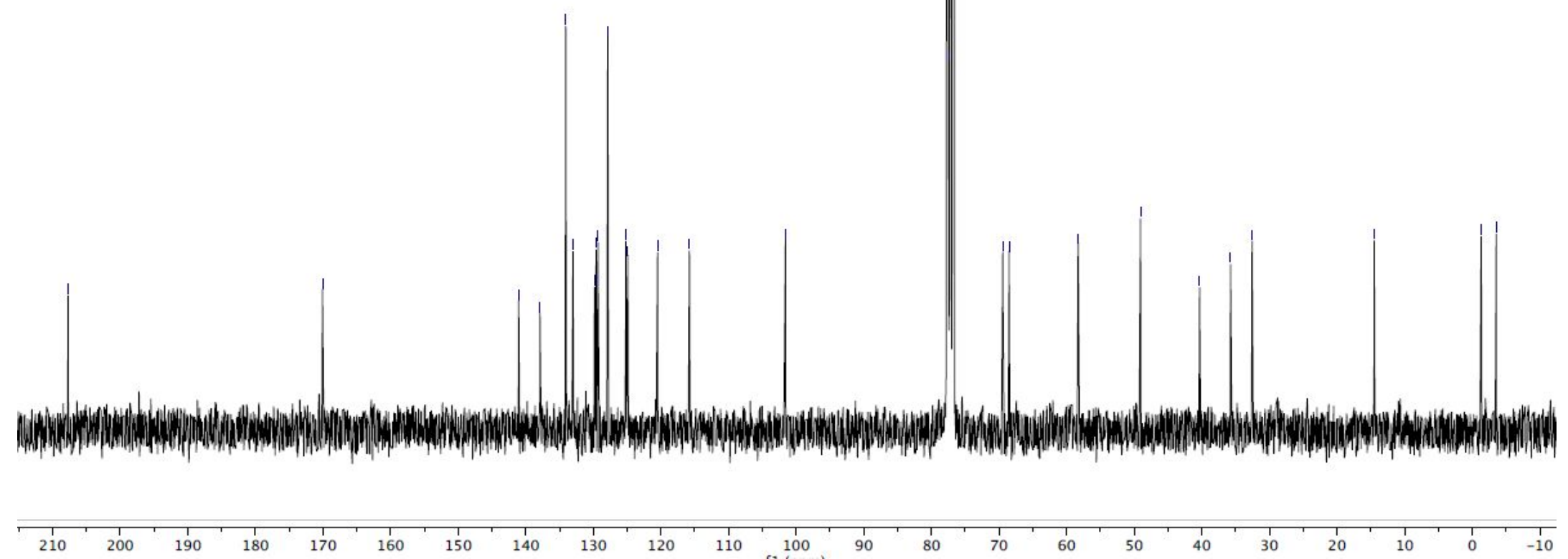


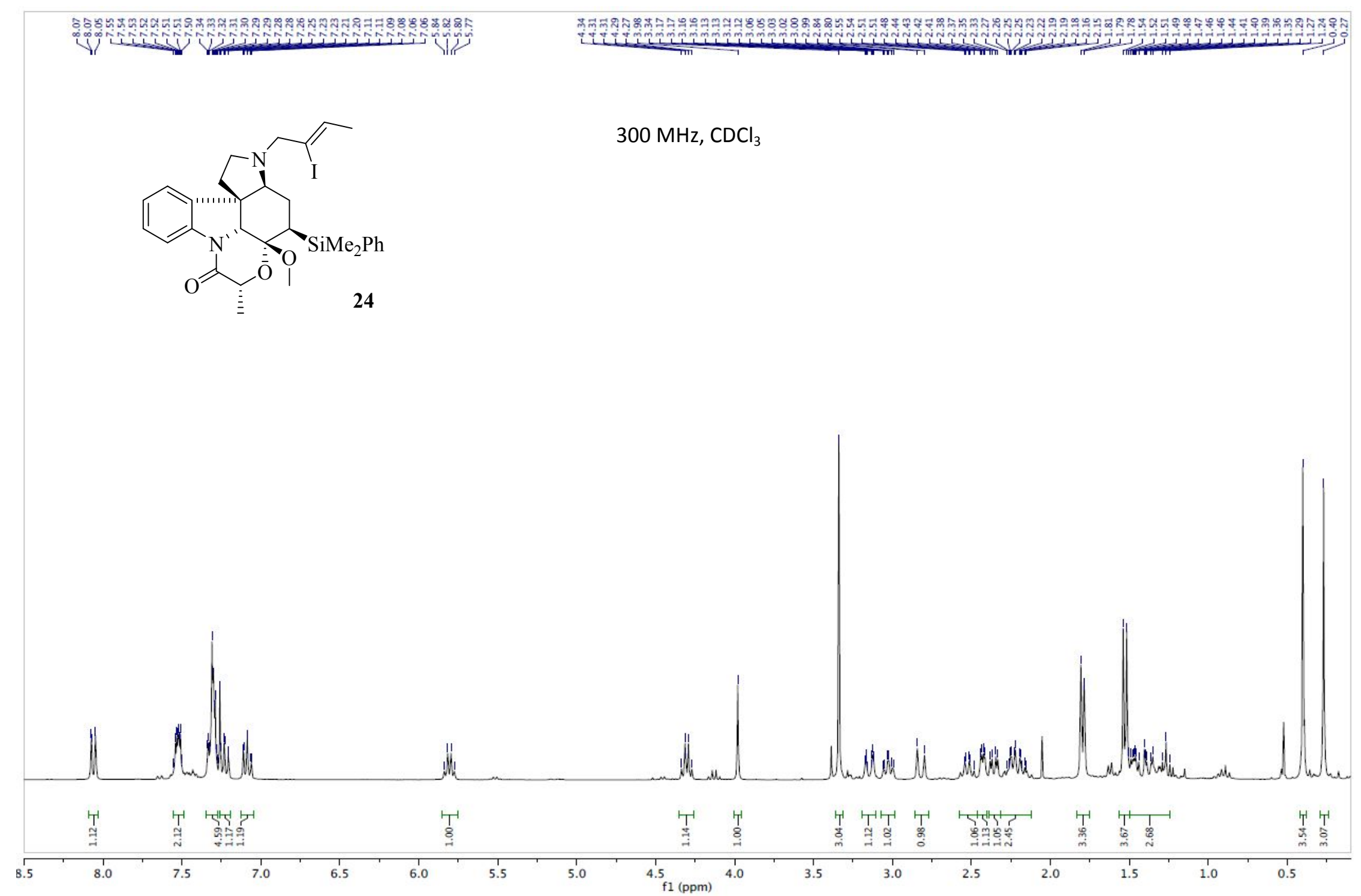




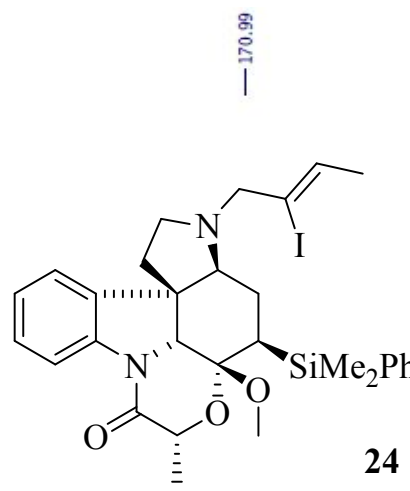

$75 \mathrm{MHz}^{\mathrm{CDCl}_{3}}$
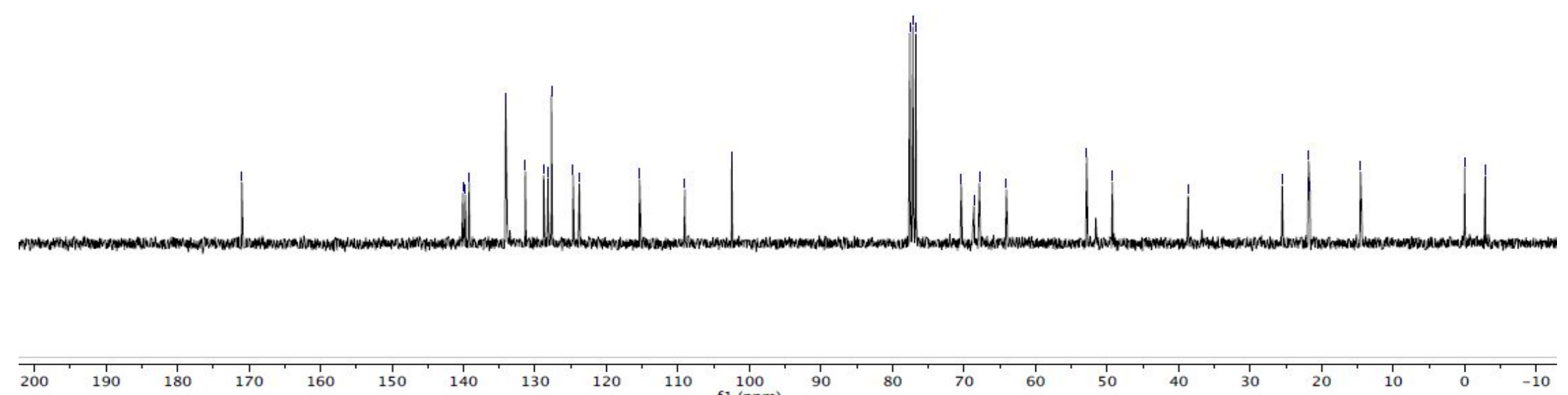


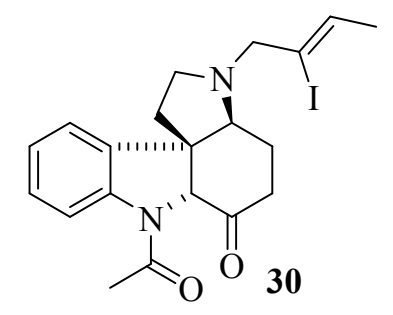

$300 \mathrm{MHz}, \mathrm{CDCl}_{3}$

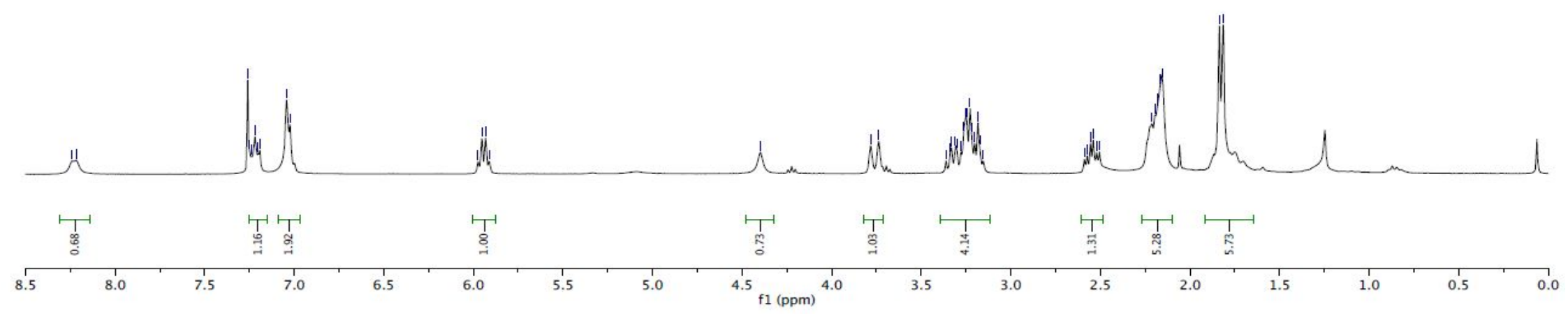



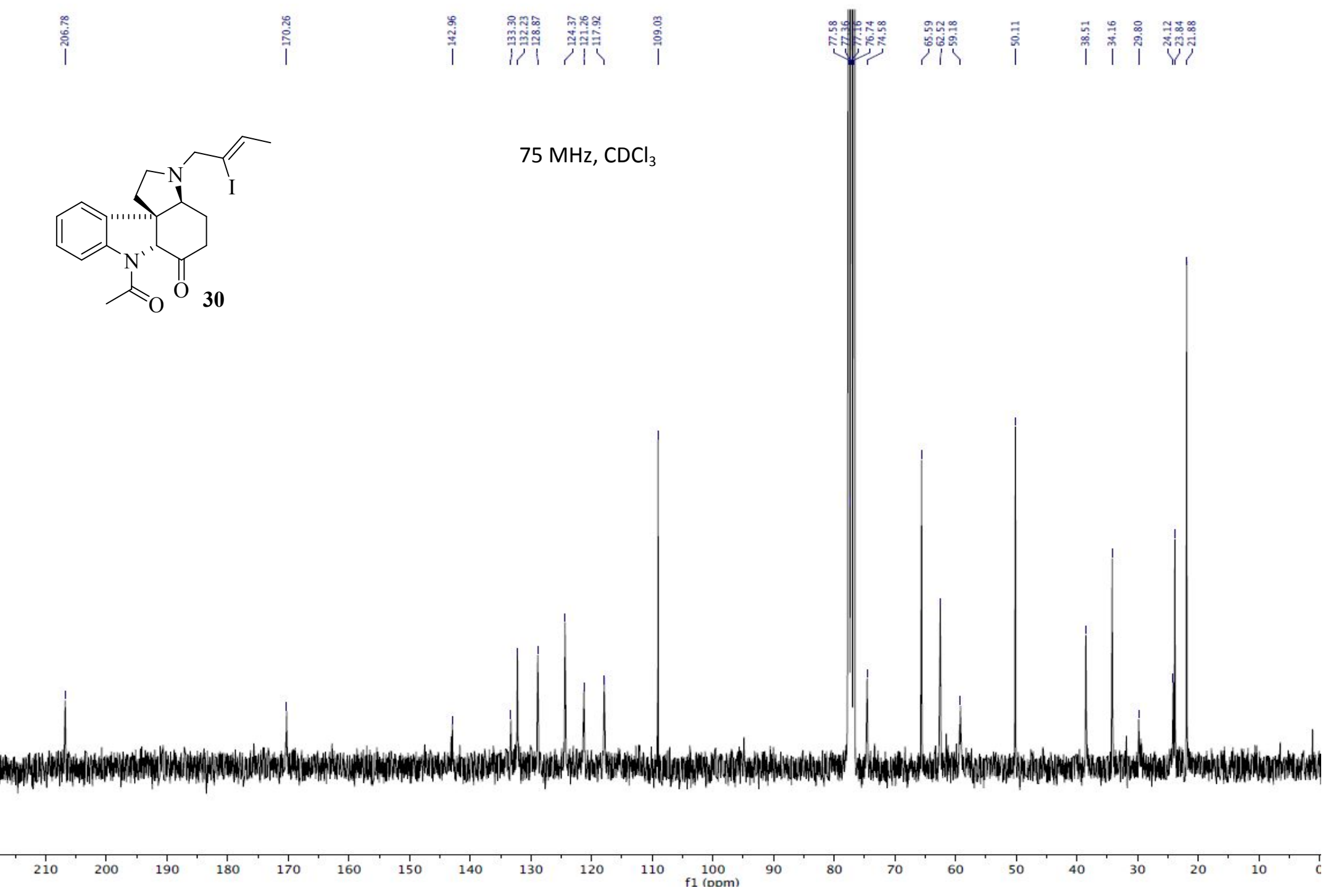


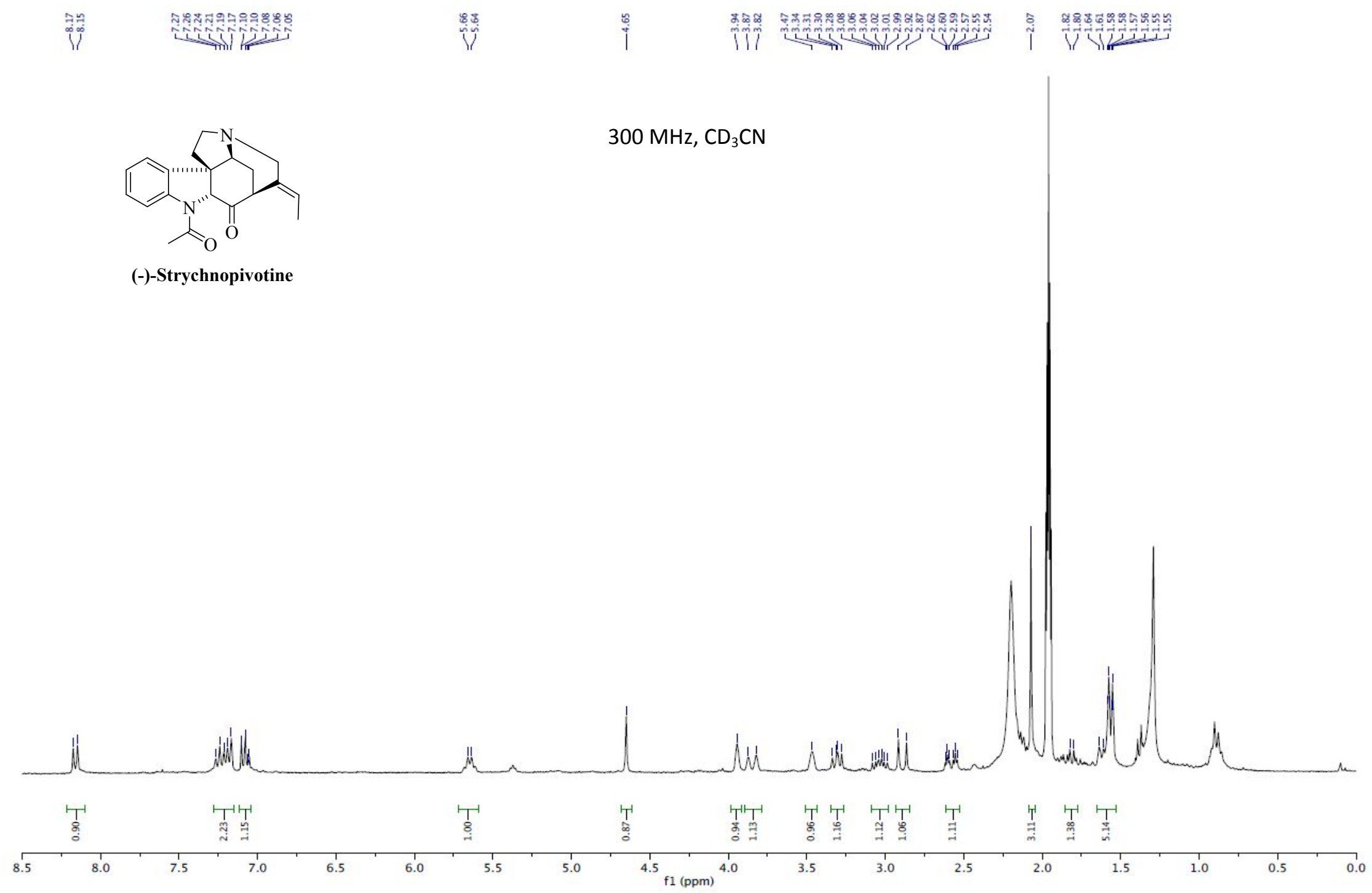




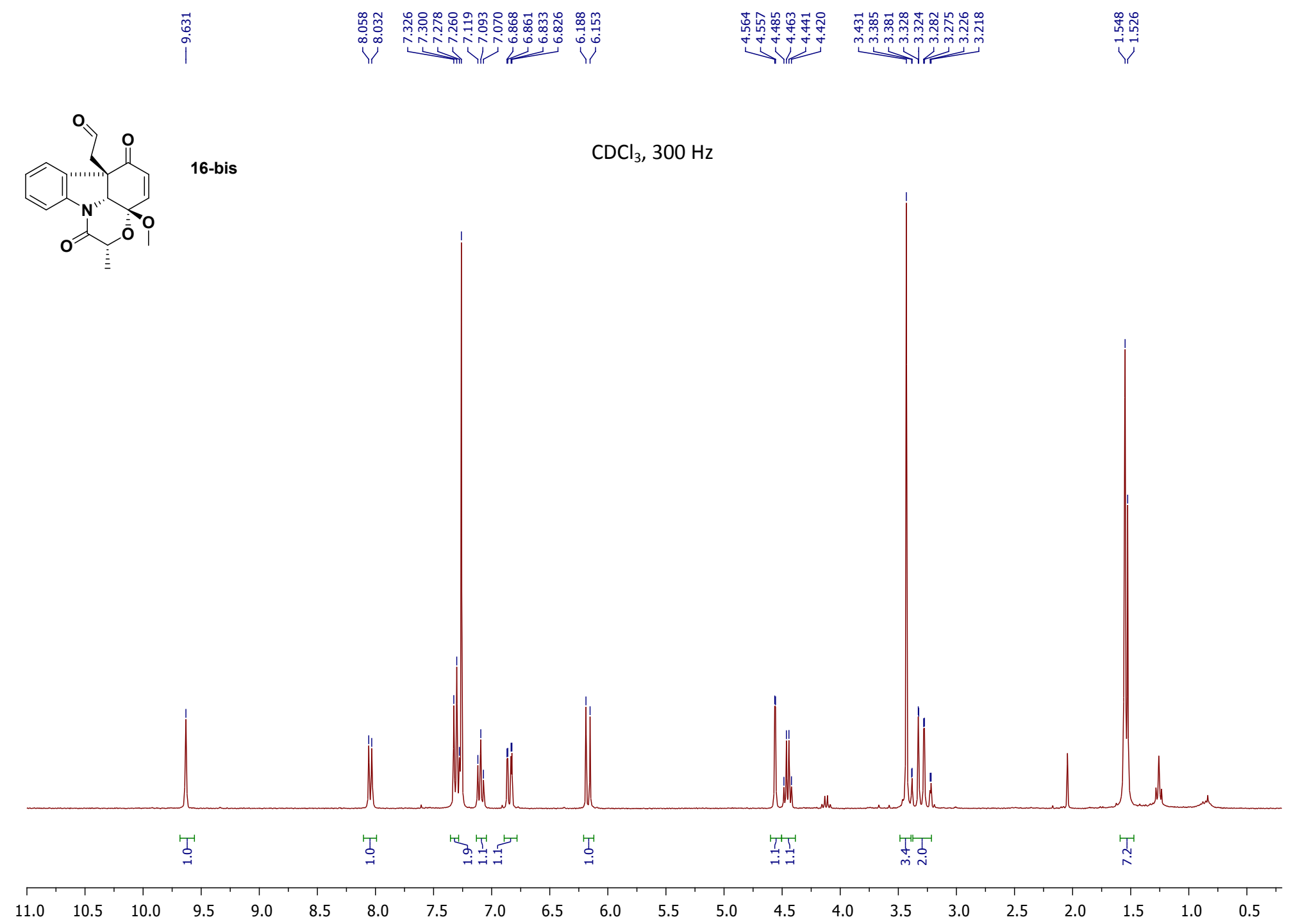




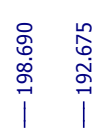

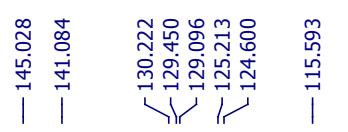

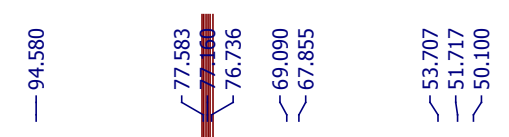

$\stackrel{\substack{0 \\ \stackrel{+}{+}}}{\stackrel{1}{1}}$

16-bis

$\mathrm{CDCl}_{3}, 75 \mathrm{MHz}$

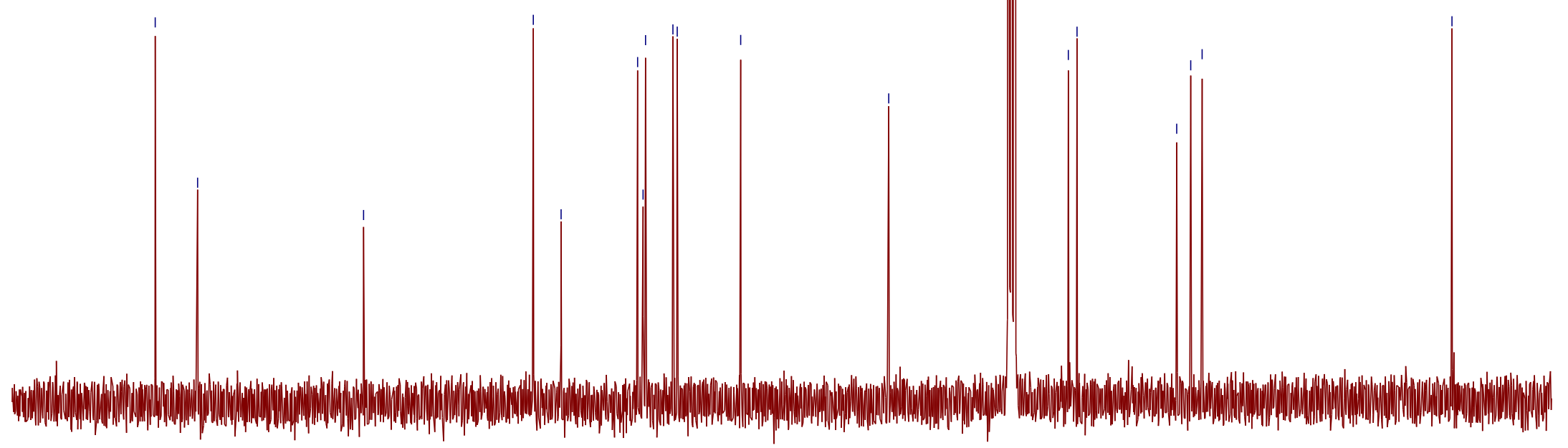

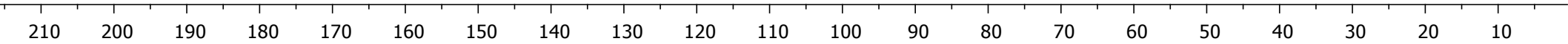




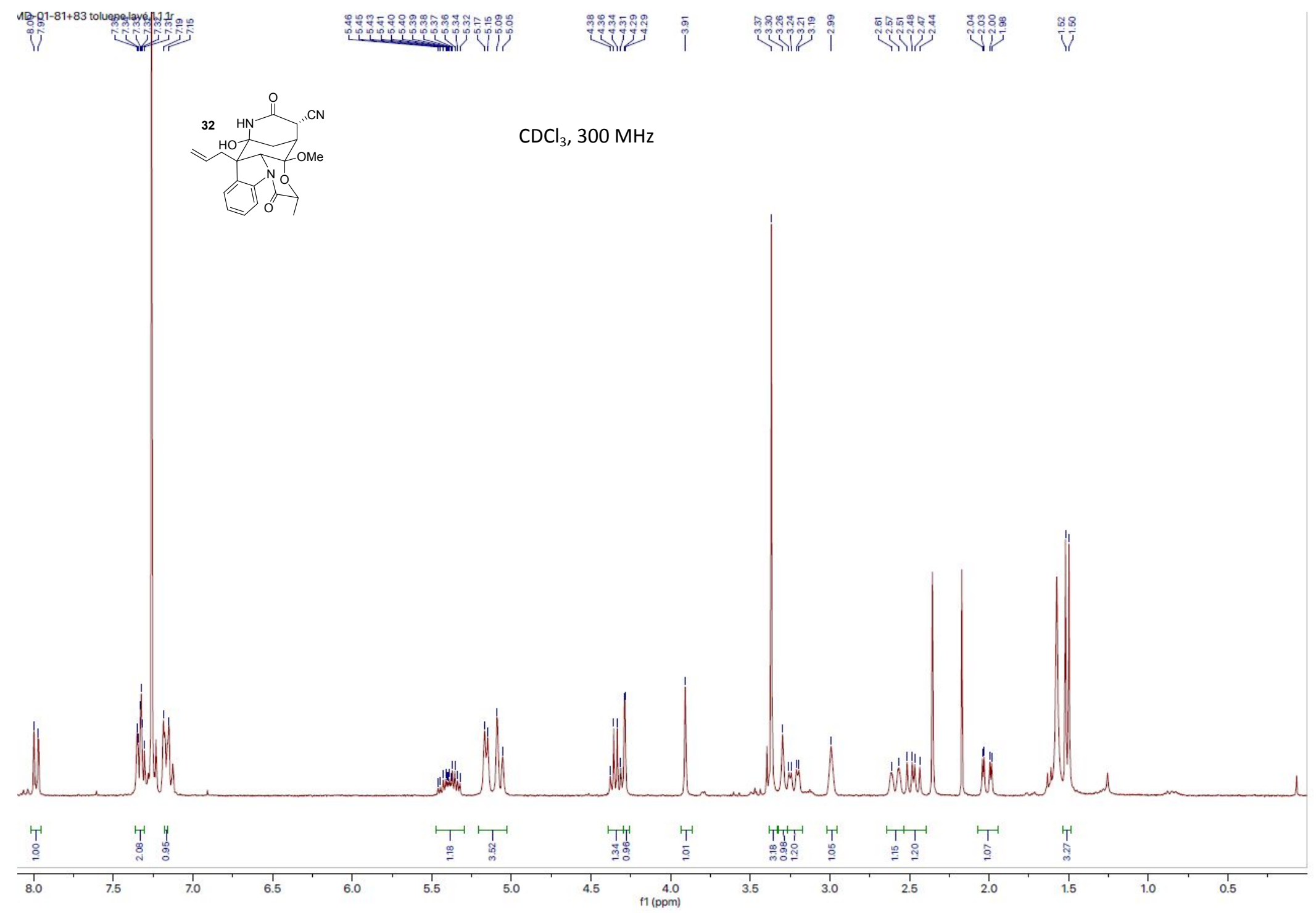



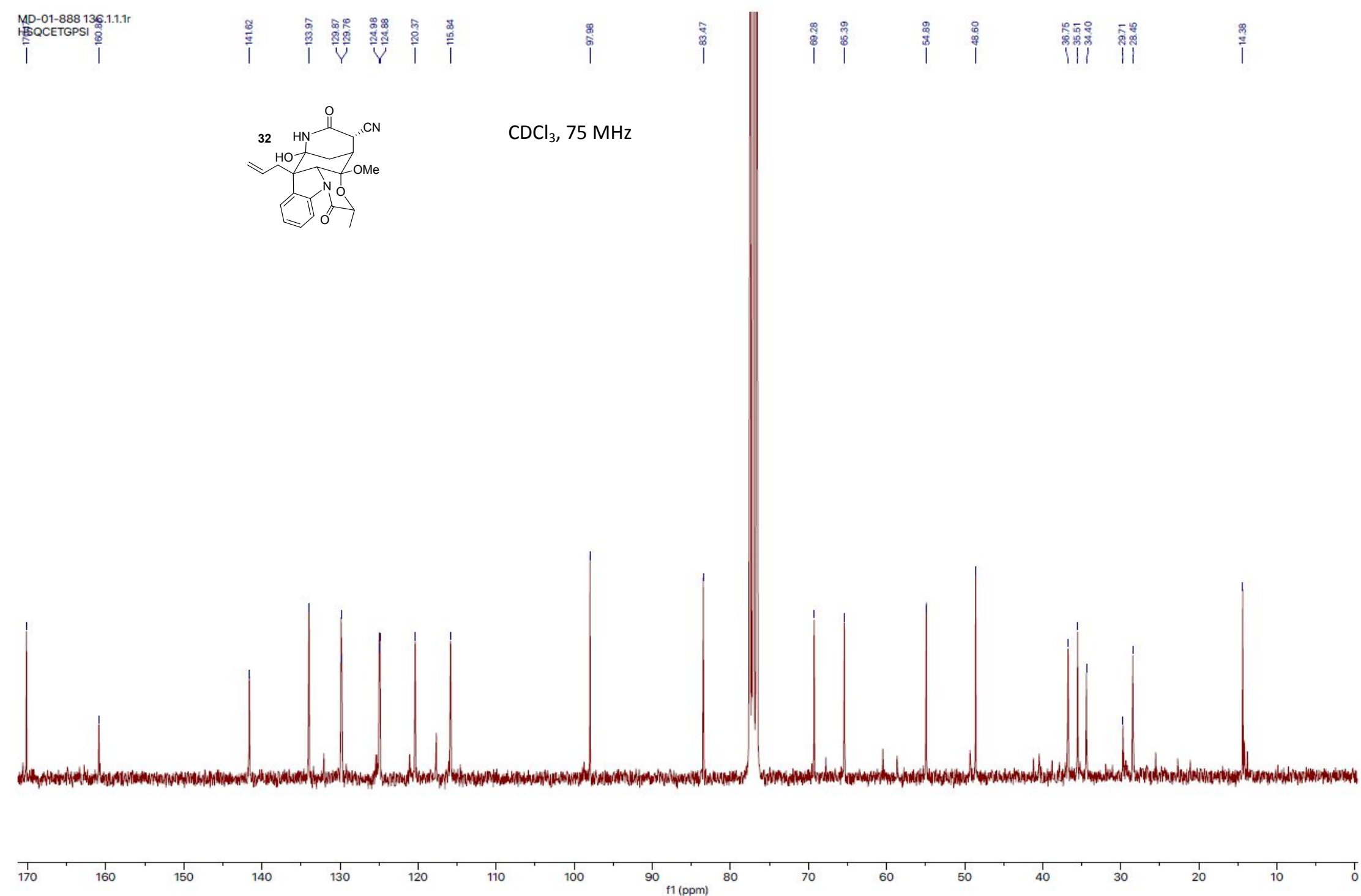

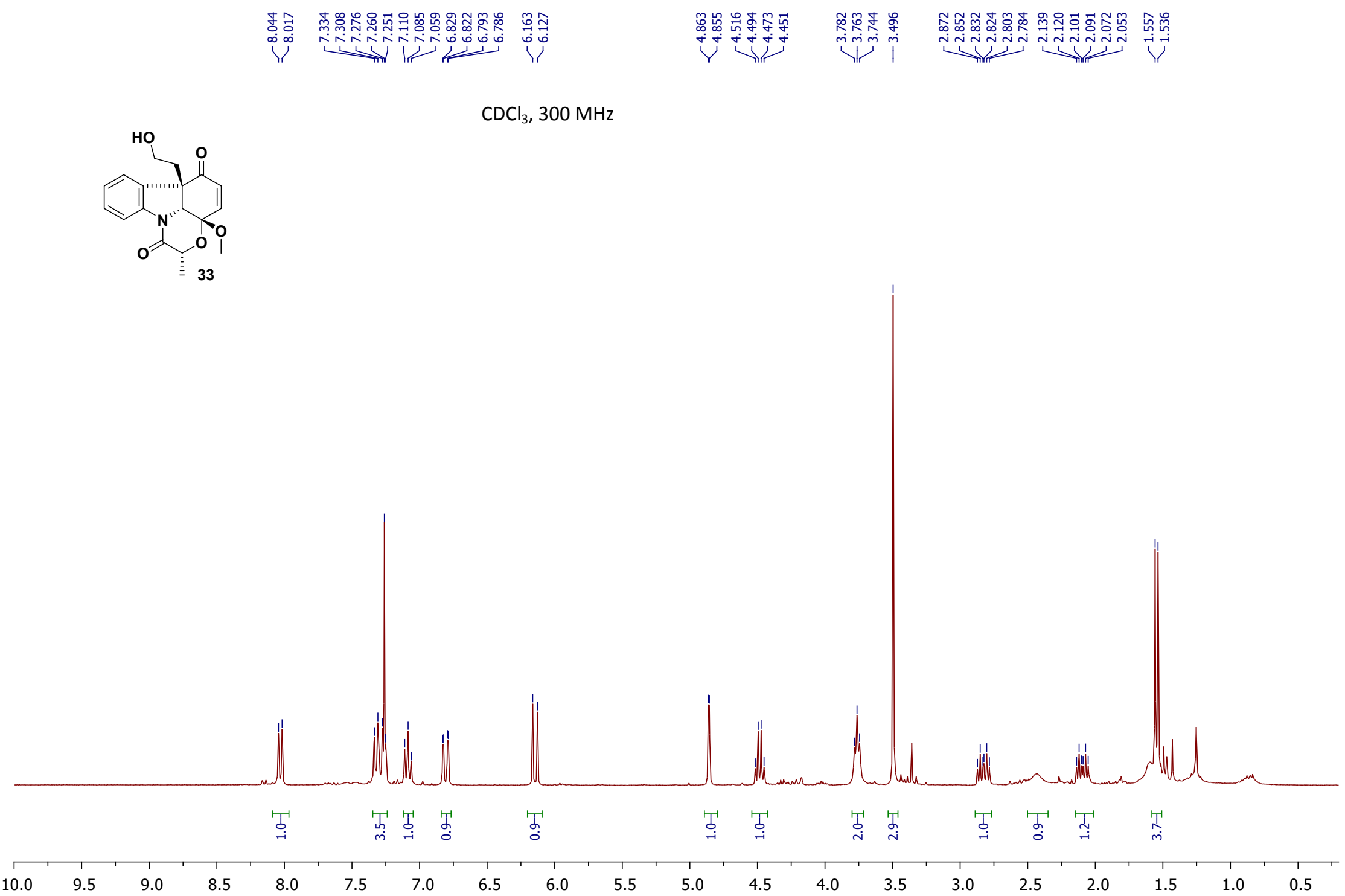

$\mathrm{CDCl}_{3}, 300 \mathrm{MHz}$ 

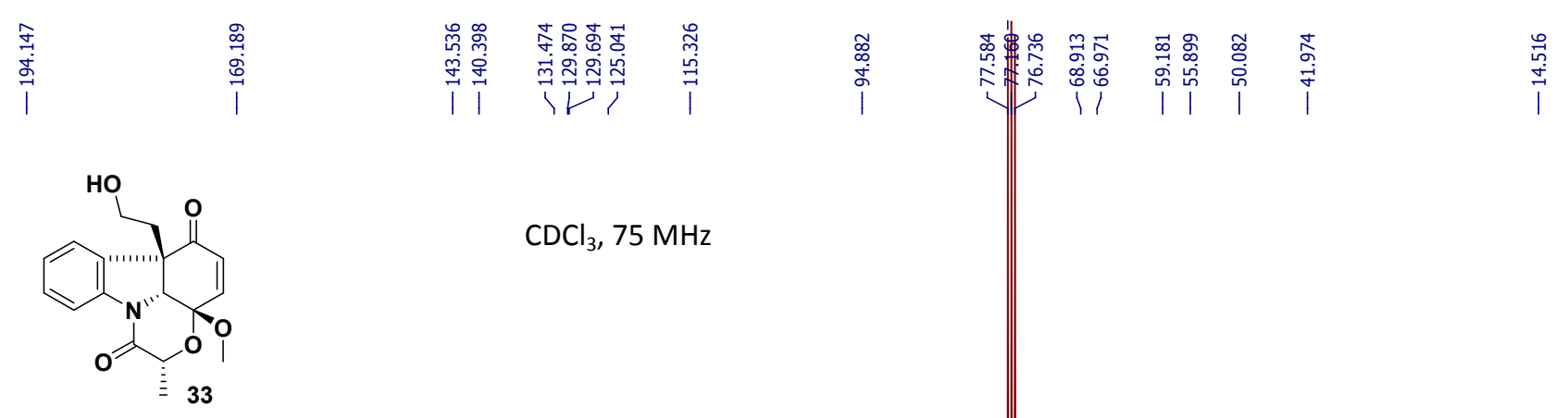

$\mathrm{CDCl}_{3}, 75 \mathrm{MHz}$

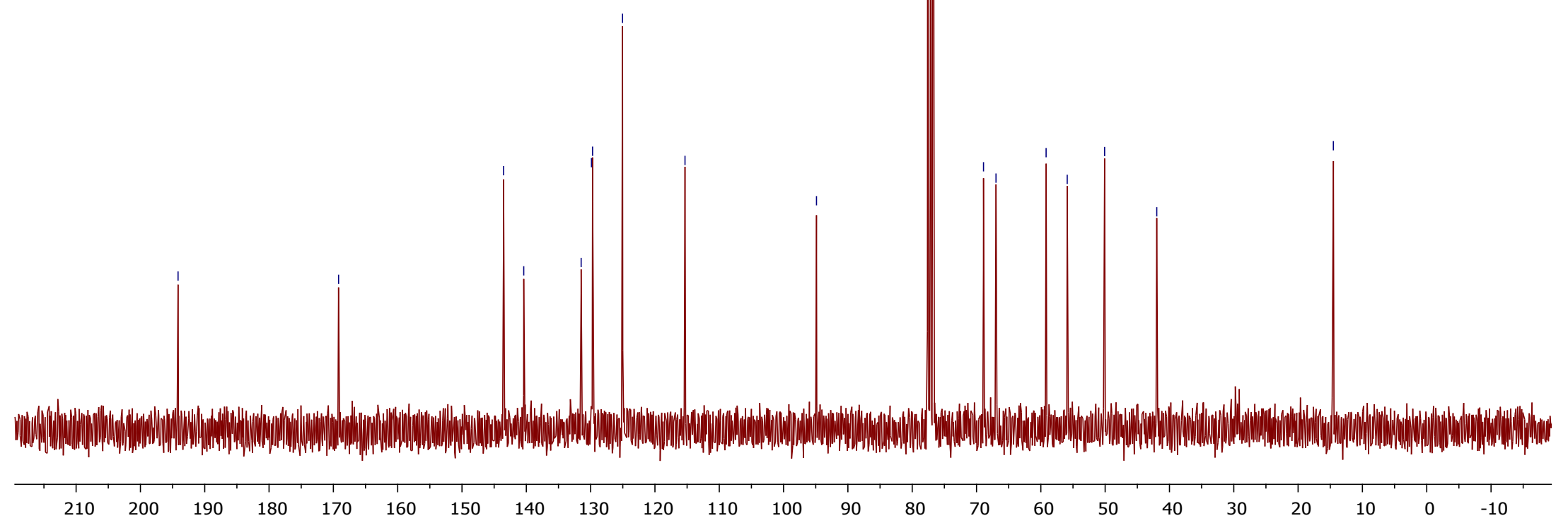




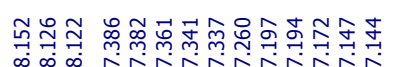

4

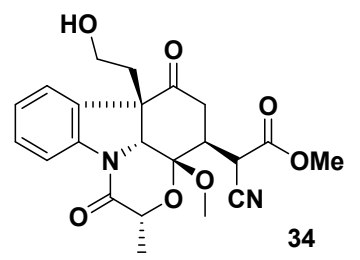

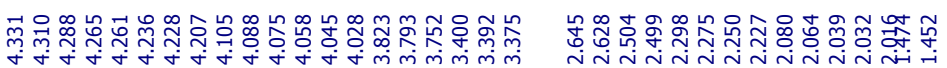 \\ तin}

$\mathrm{CDCl}_{3}, 300 \mathrm{MHz}$

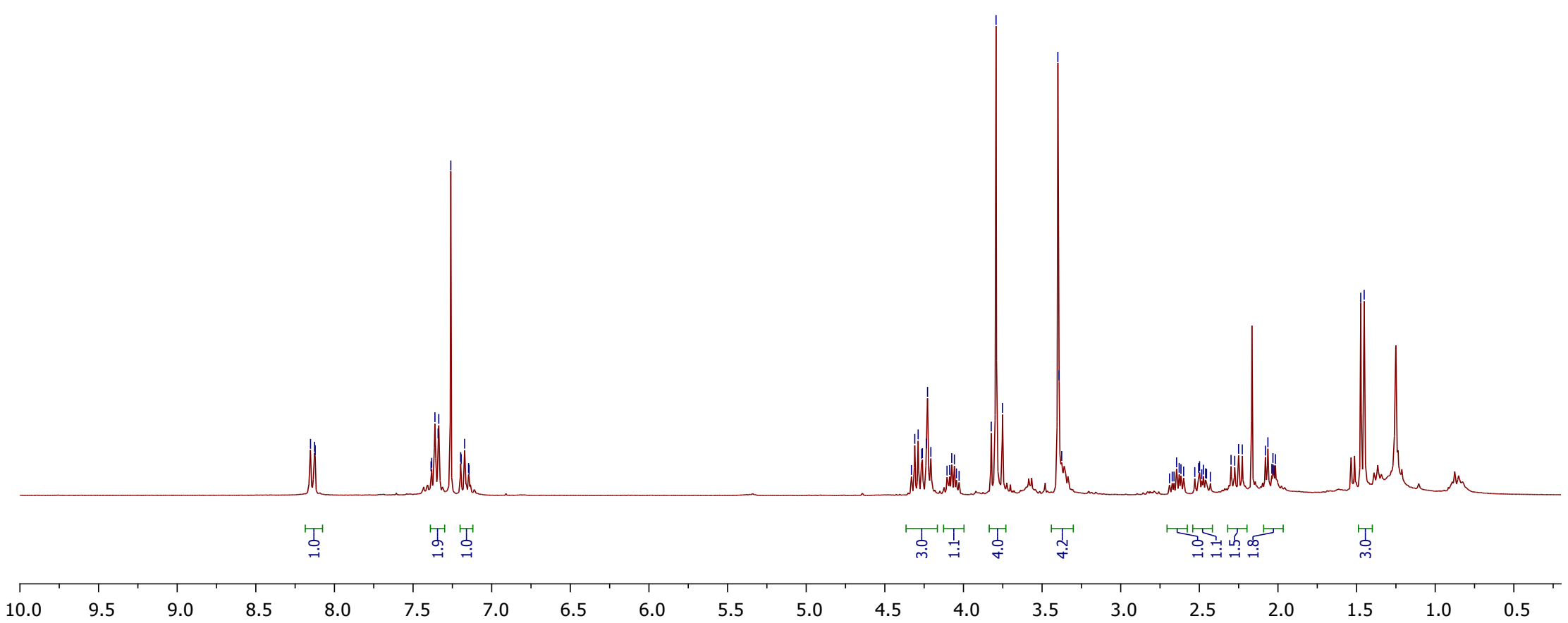



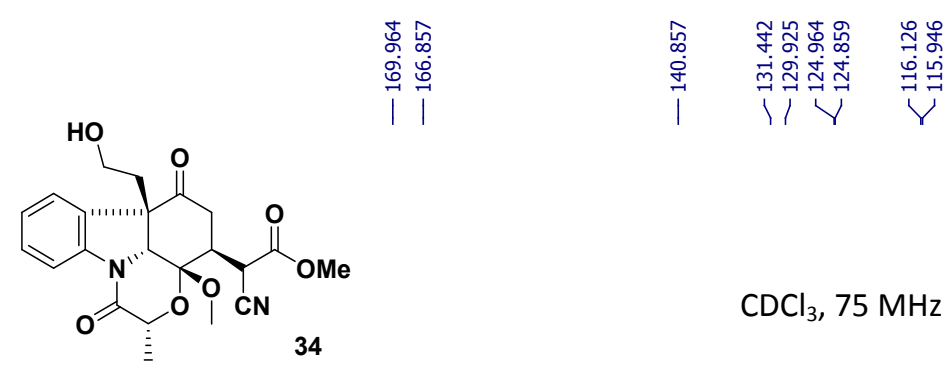

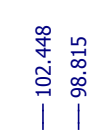

\section{$\sqrt{n}$}

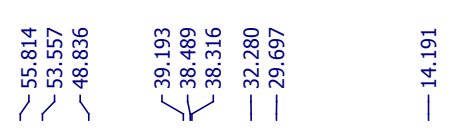

$\mathrm{CDCl}_{3}, 75 \mathrm{MHz}$

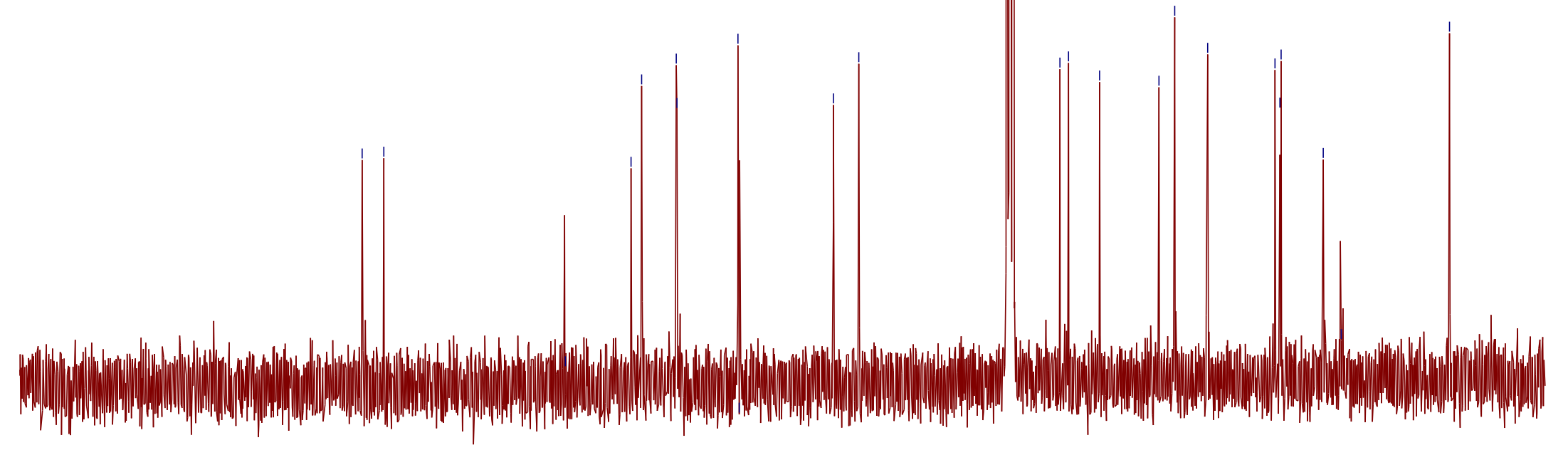

$\begin{array}{lllll}210 & 200 & 190 & 180 & 170\end{array}$

$\begin{array}{lll}150 & 140 & 130\end{array}$

$120 \quad 110$

$100 \quad 90$

$80 \quad 70$

$60 \quad 50$

$40 \quad 30 \quad 20$

10 


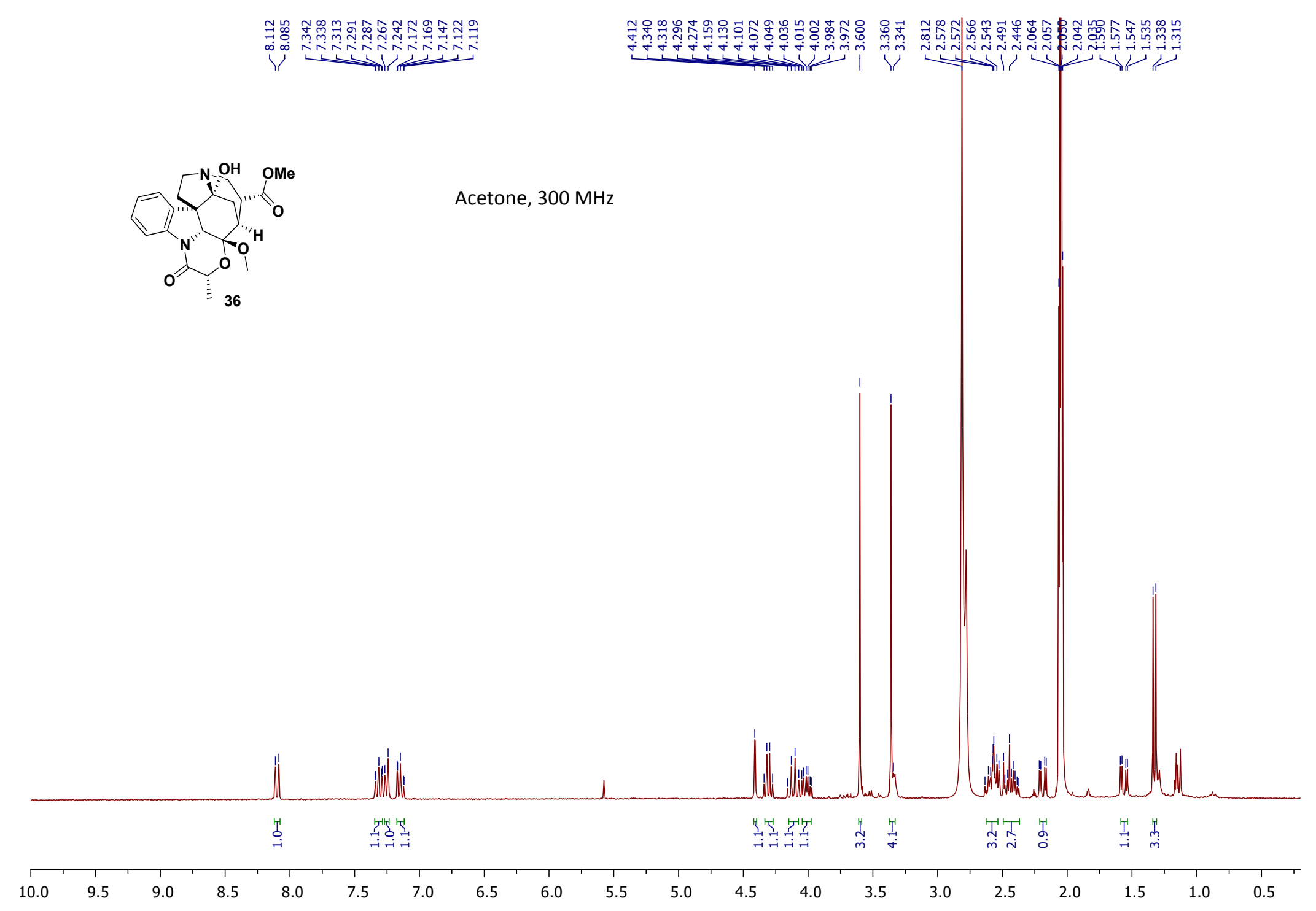



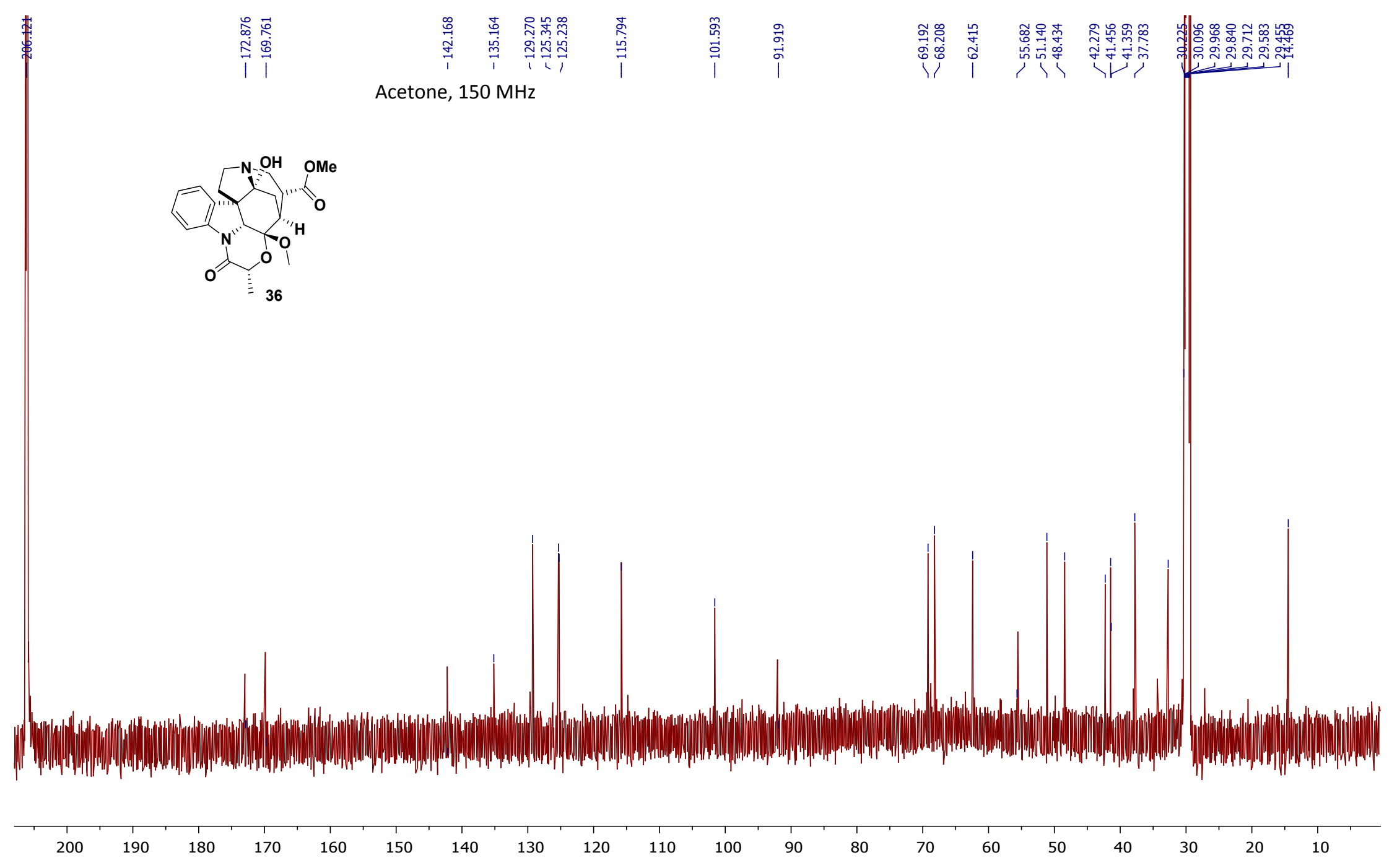
NOE ${ }^{1} \mathrm{H}-{ }^{1} \mathrm{H}$ Peak at $3.60 \mathrm{ppm}$ :

Acetone, $600 \mathrm{MHz}$

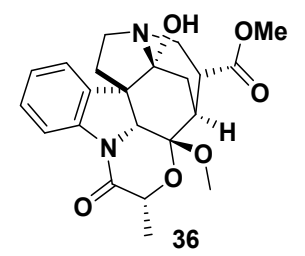

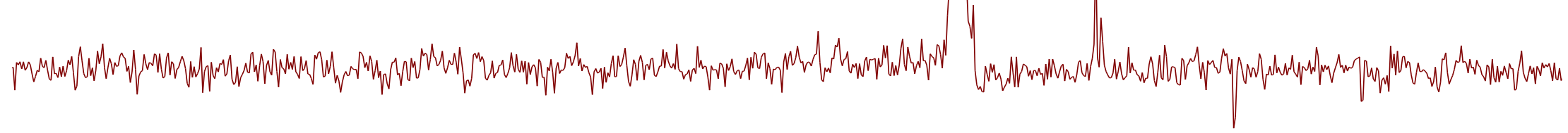

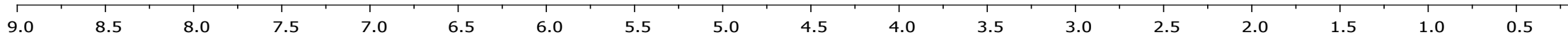




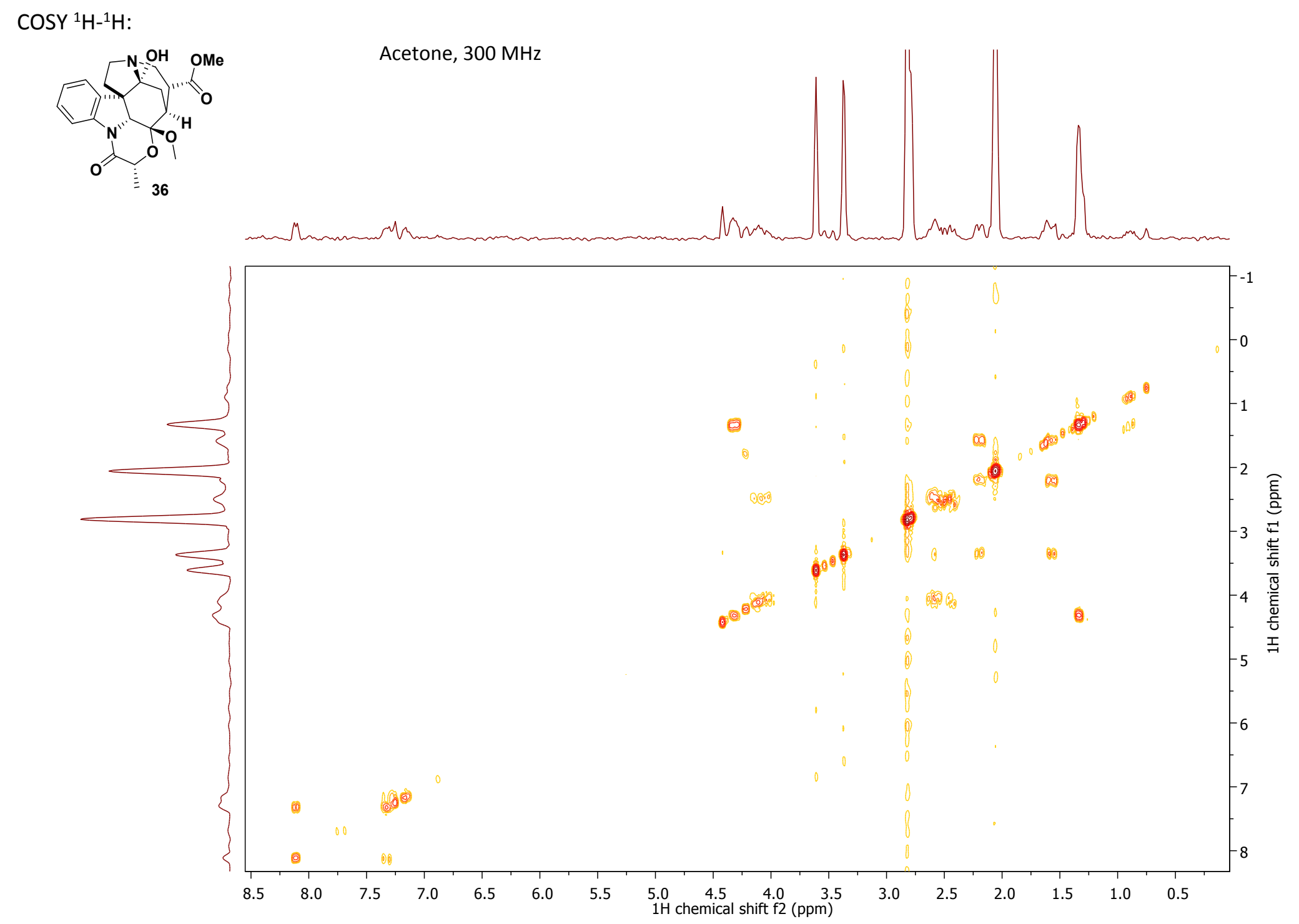




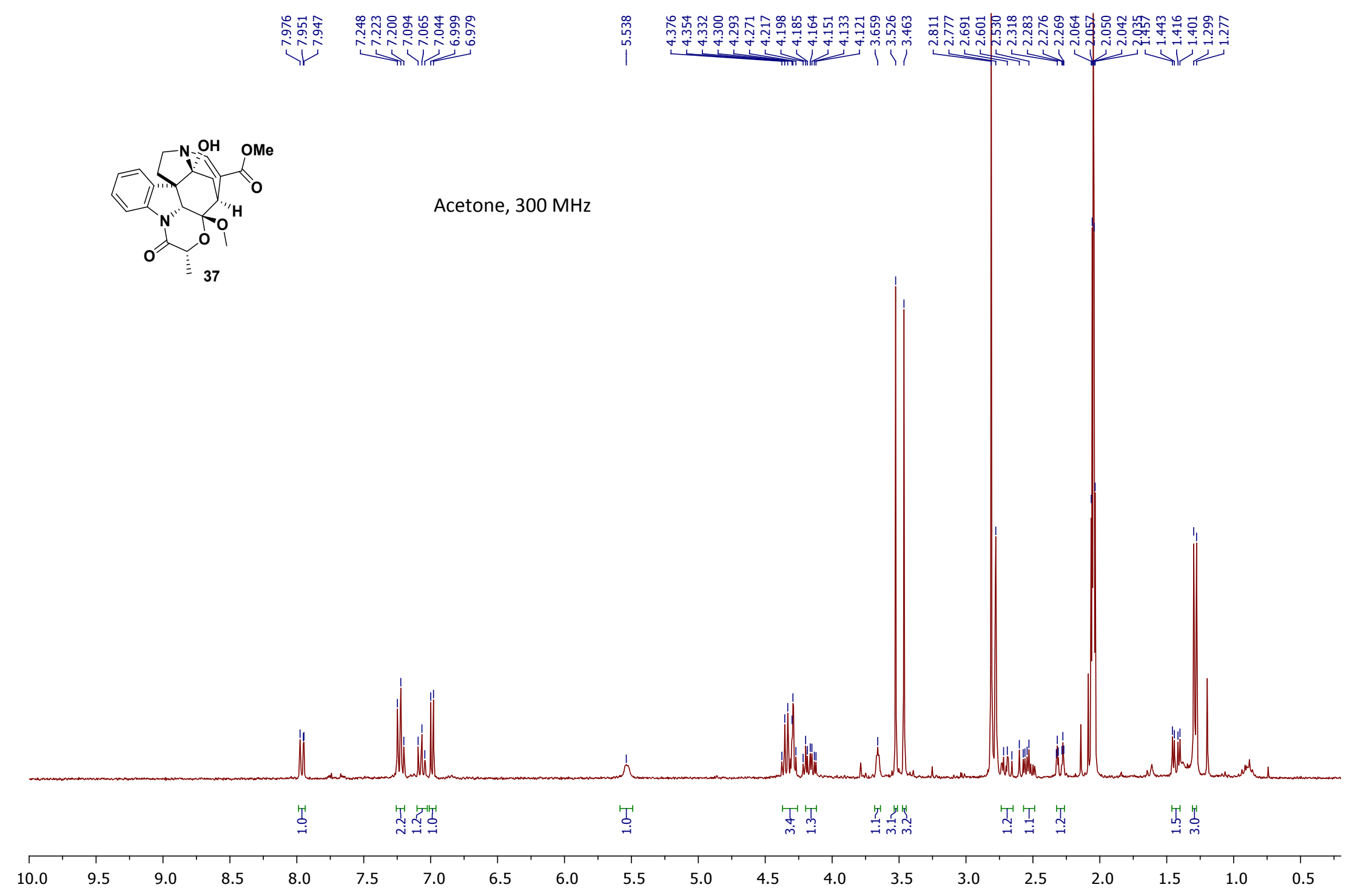




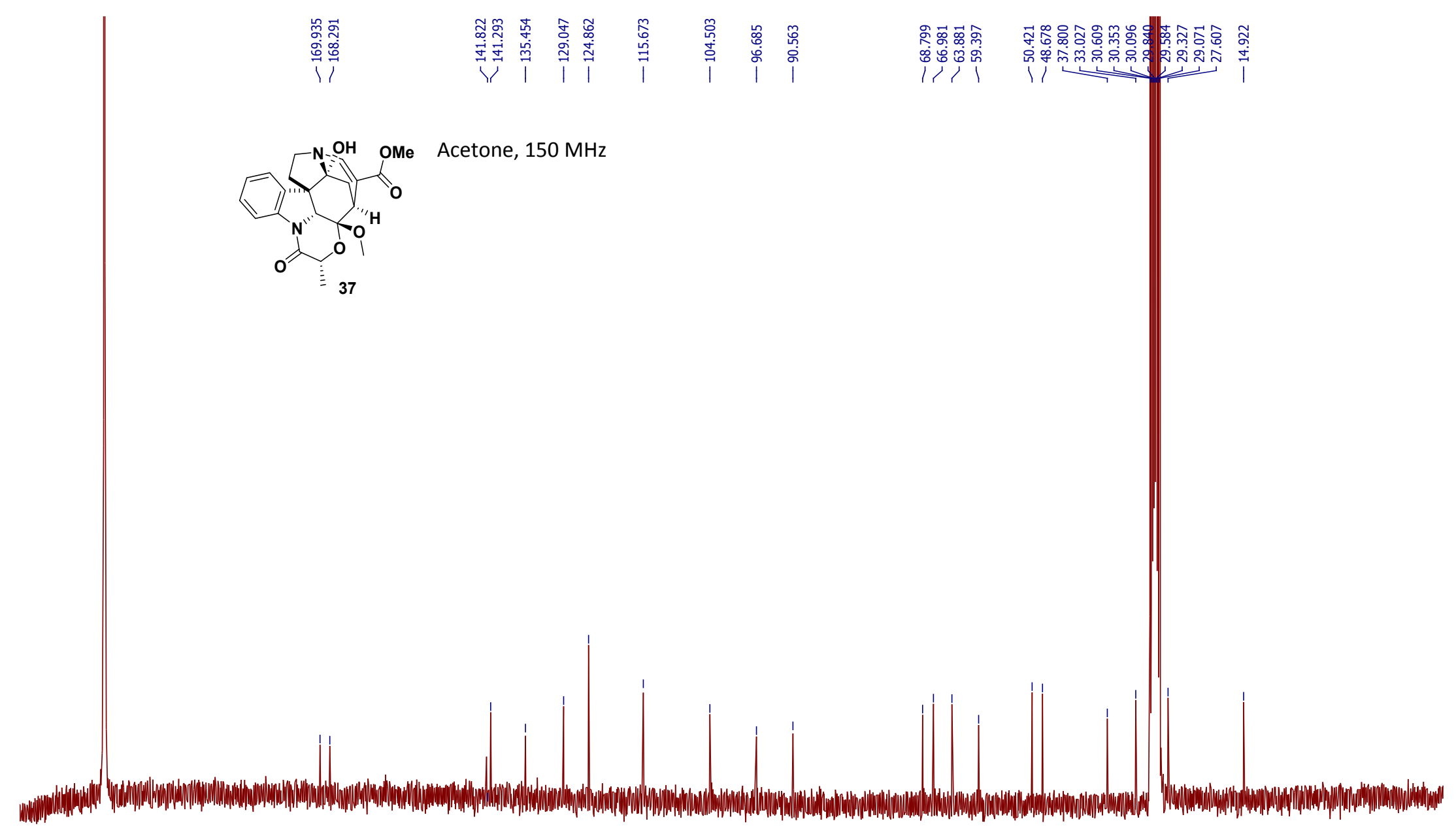




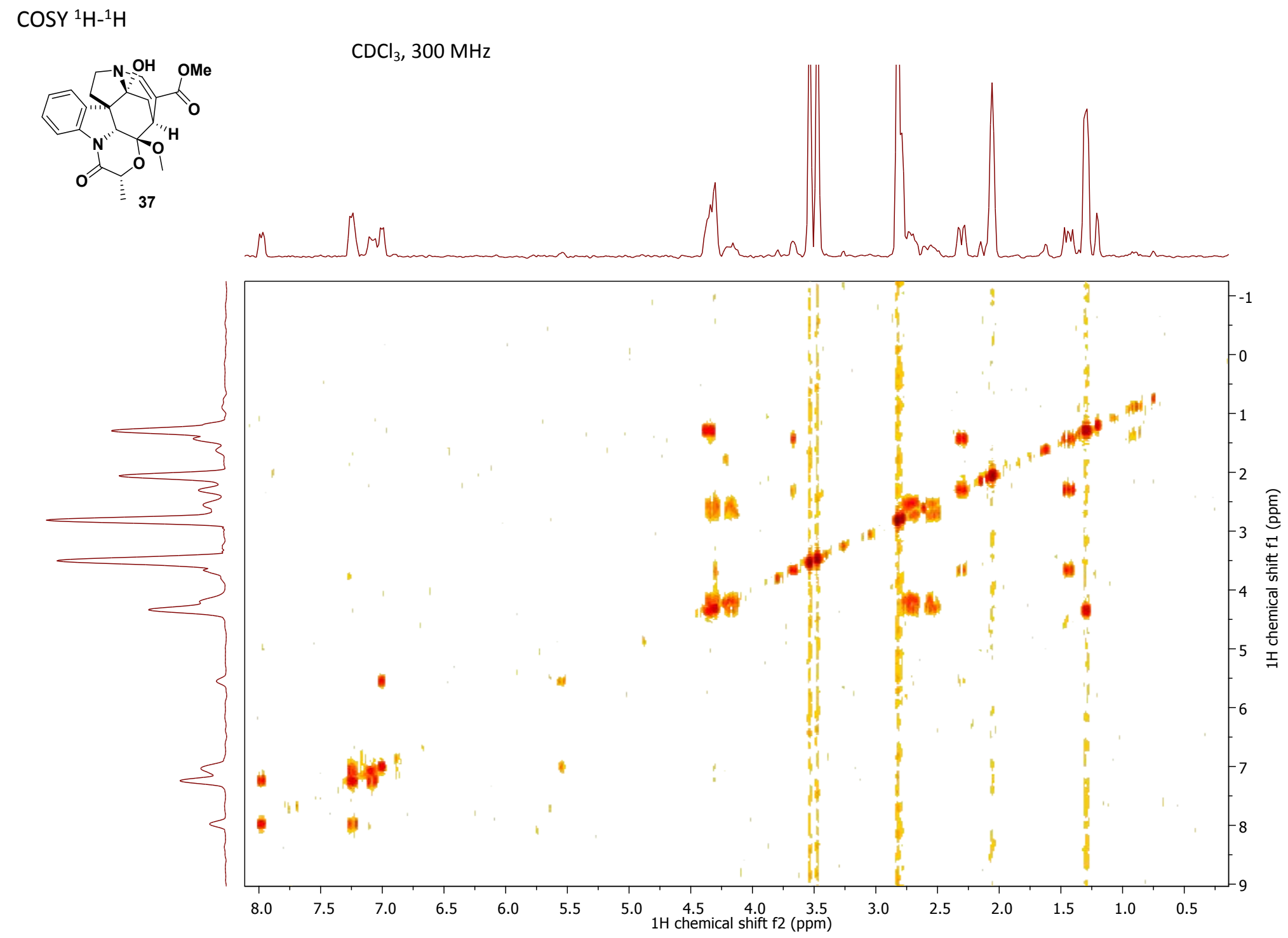




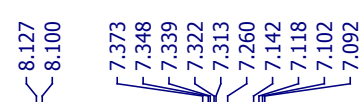

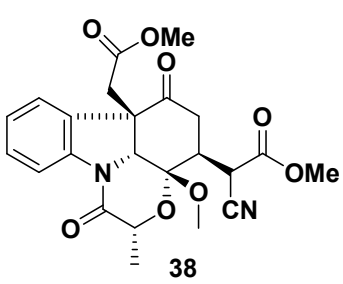

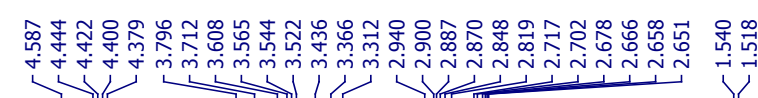

$\mathrm{CDCl}_{3}, 300 \mathrm{MHz}$

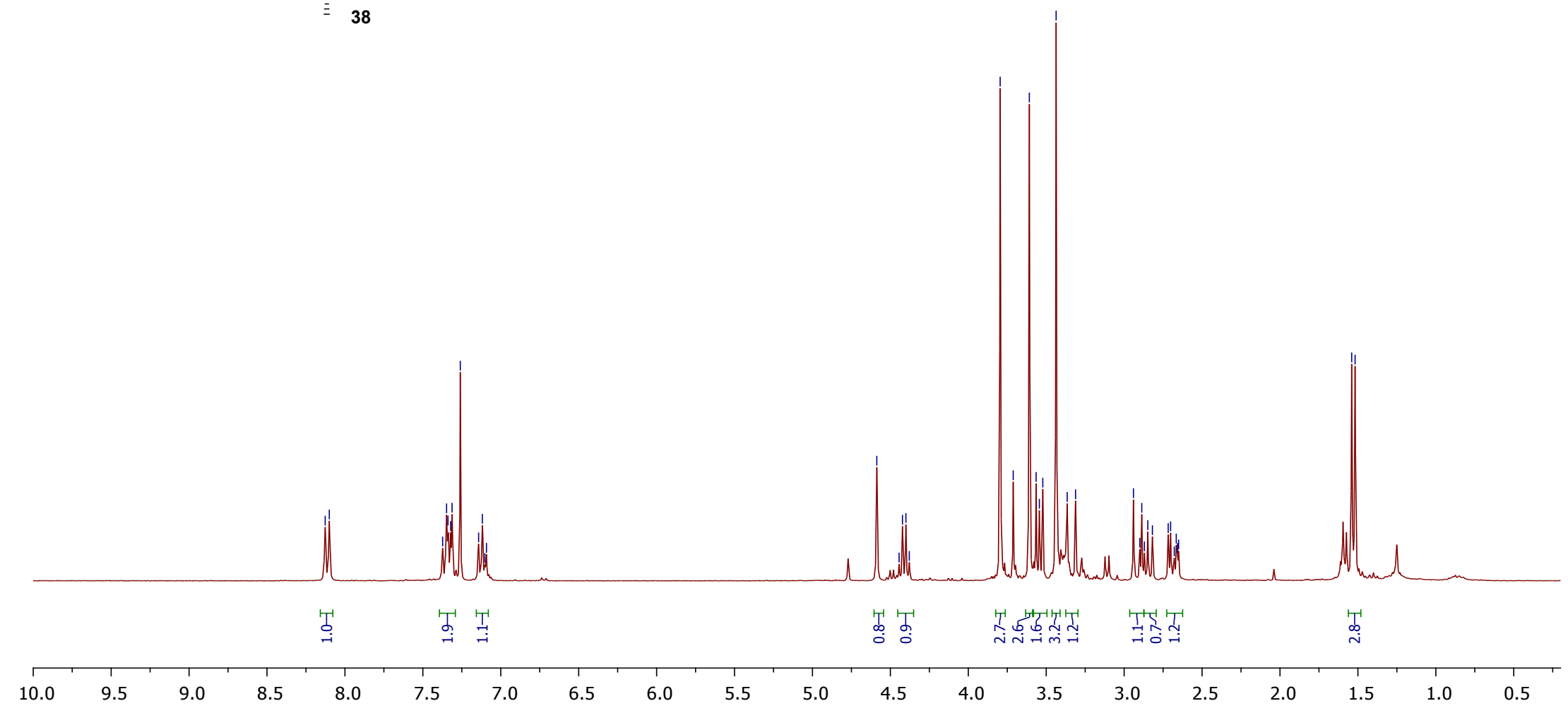



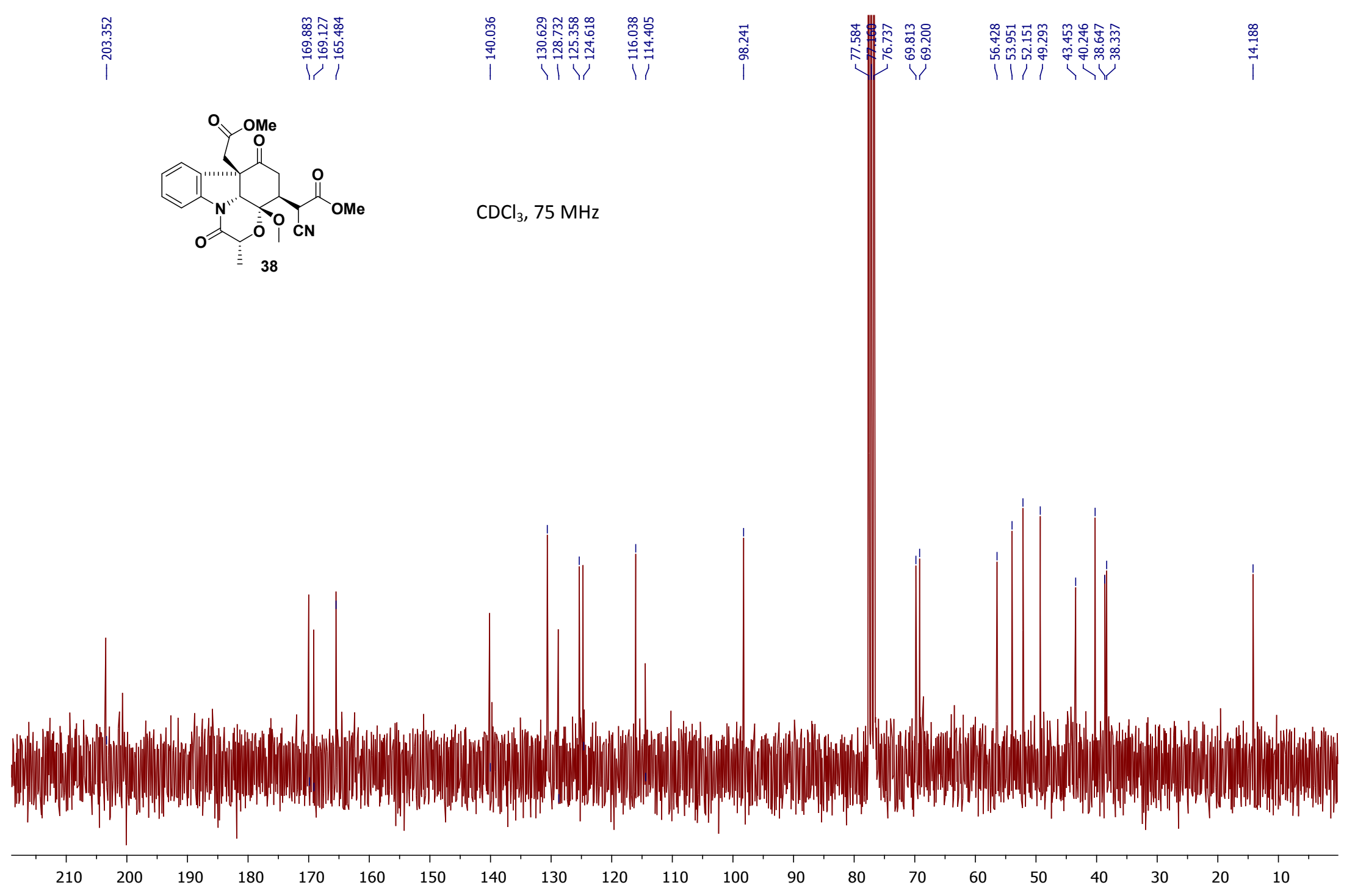


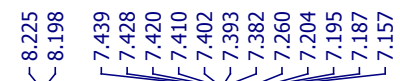

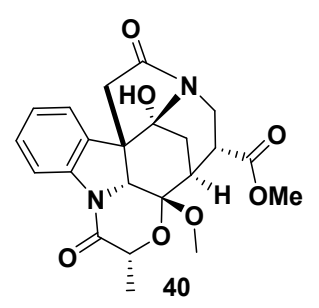

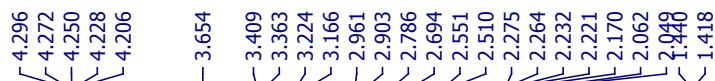

$\mathrm{CDCl}_{3}, 300 \mathrm{MHz}$

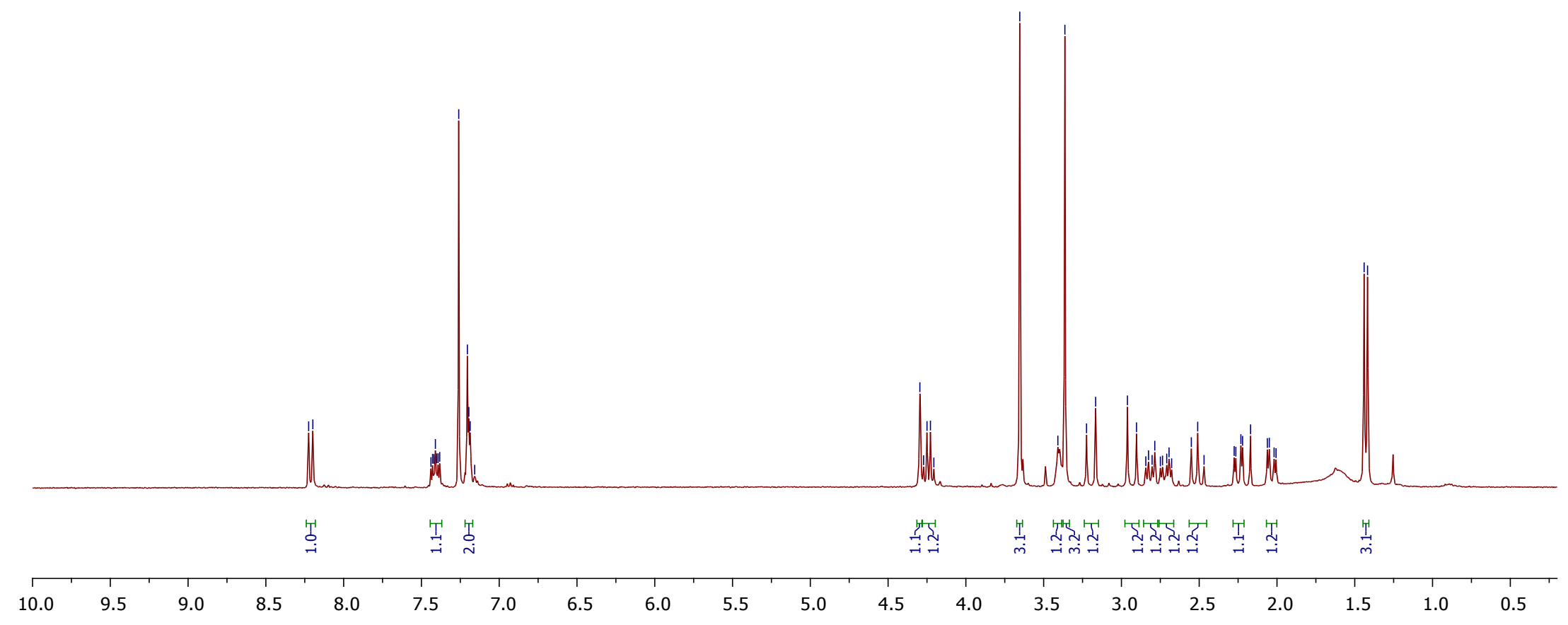




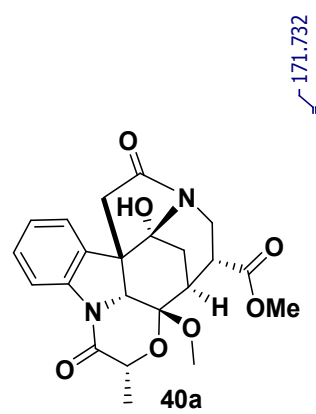

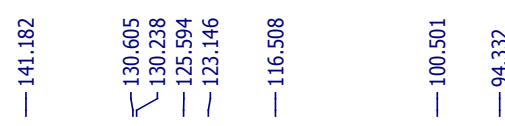

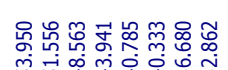

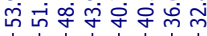

$\mathrm{CDCl}_{3}, 75 \mathrm{MHz}$

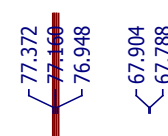

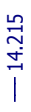

$40 a$

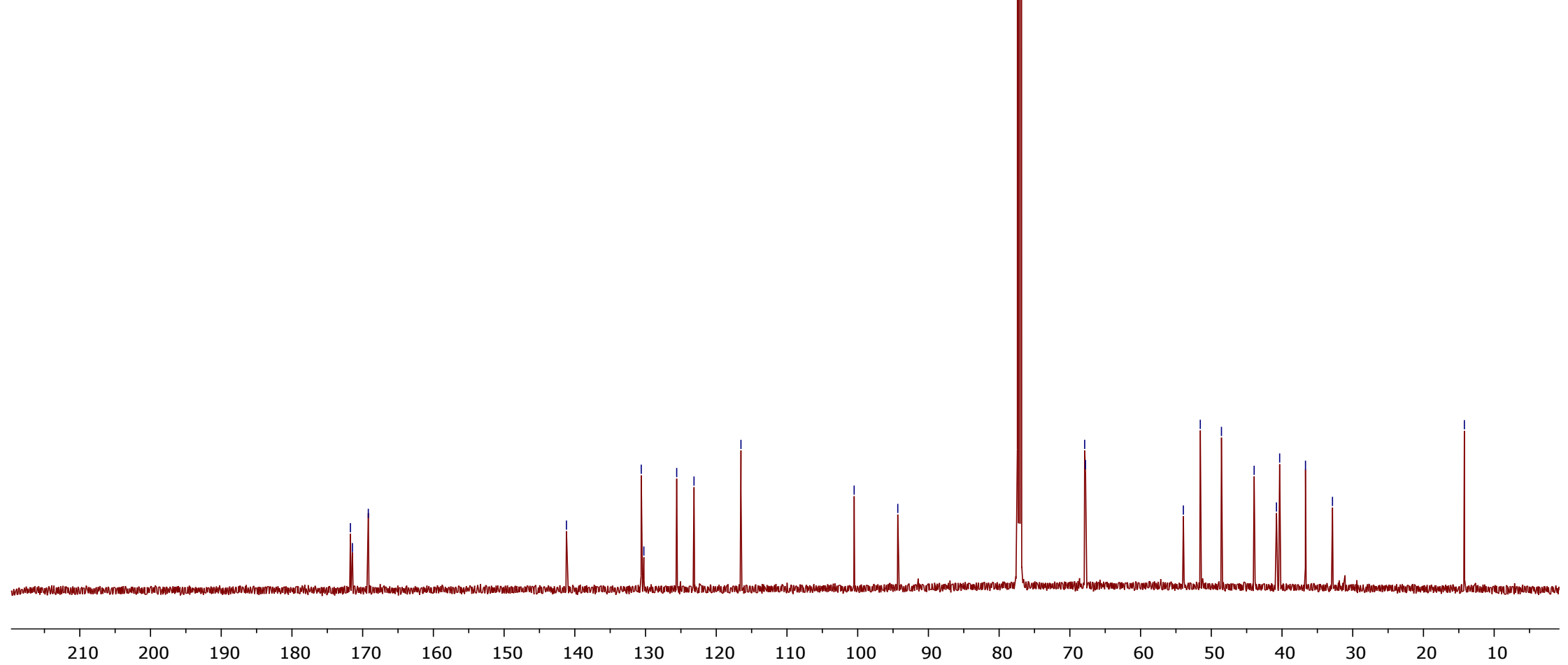


NOE ${ }^{1} \mathrm{H}-{ }^{1} \mathrm{H}$ Peak at $3.65 \mathrm{ppm}$ :

$\mathrm{CDCl}_{3}, 600 \mathrm{MHz}$

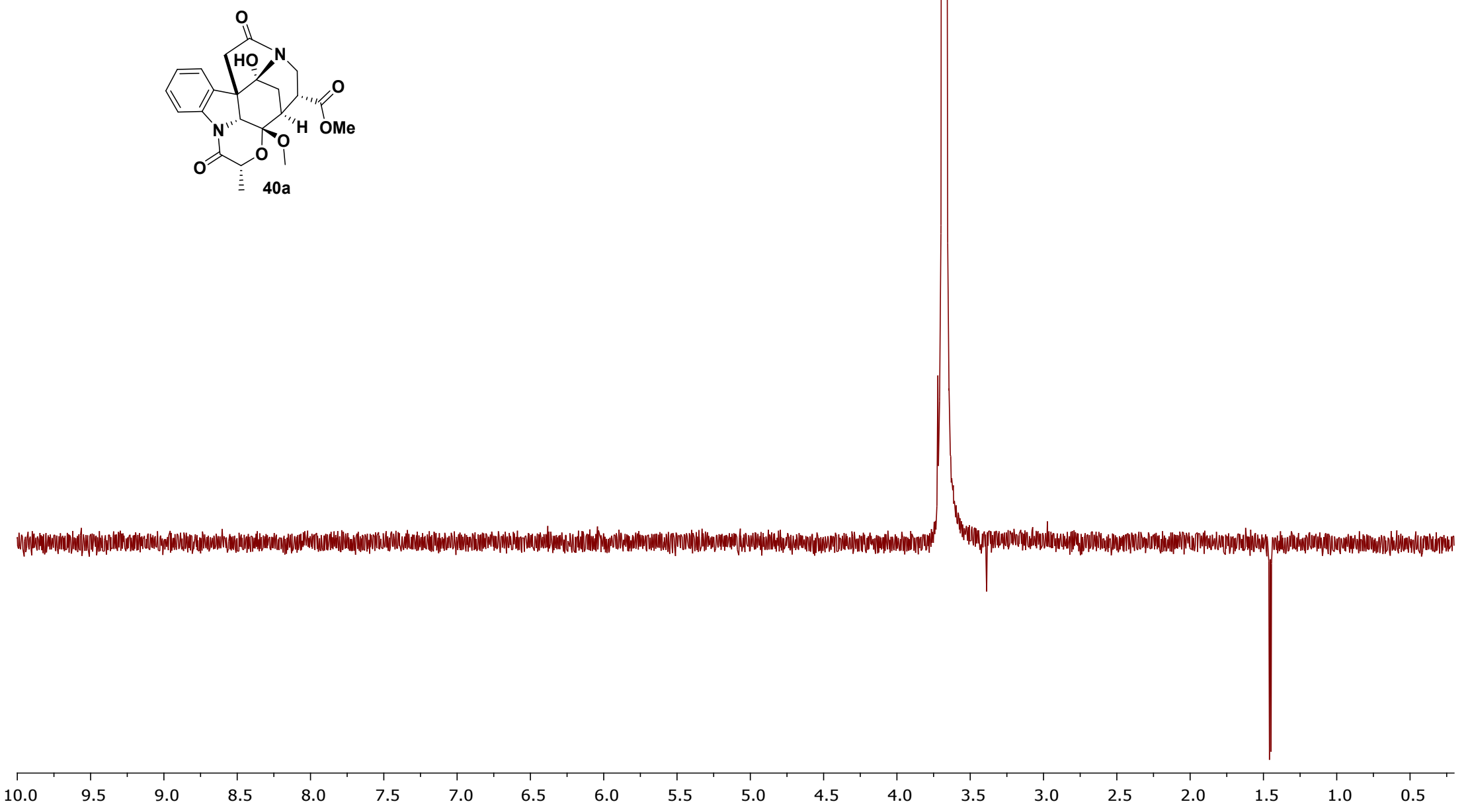


$\cos { }^{1} \mathrm{H}-{ }^{1} \mathrm{H}:$
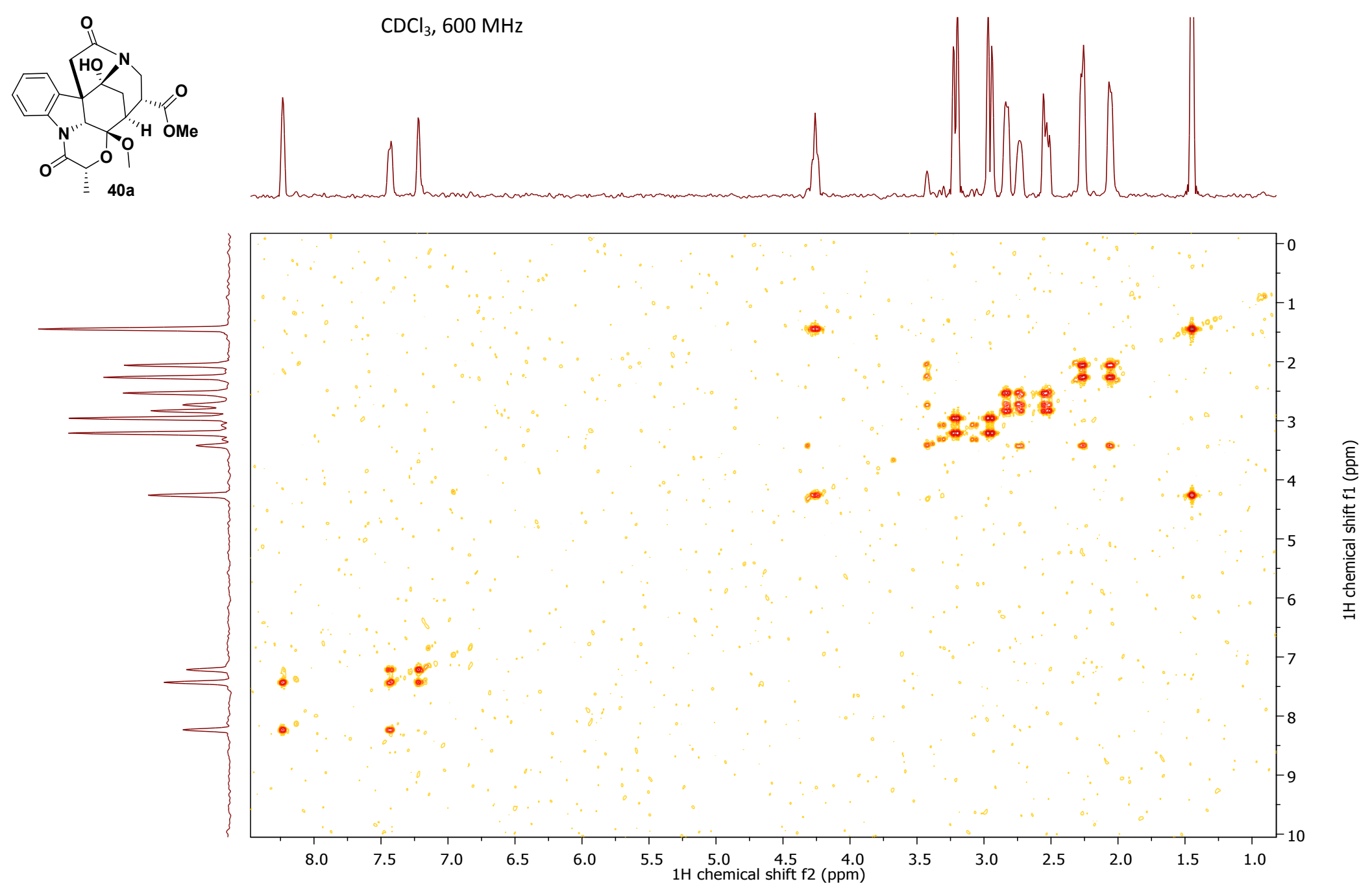


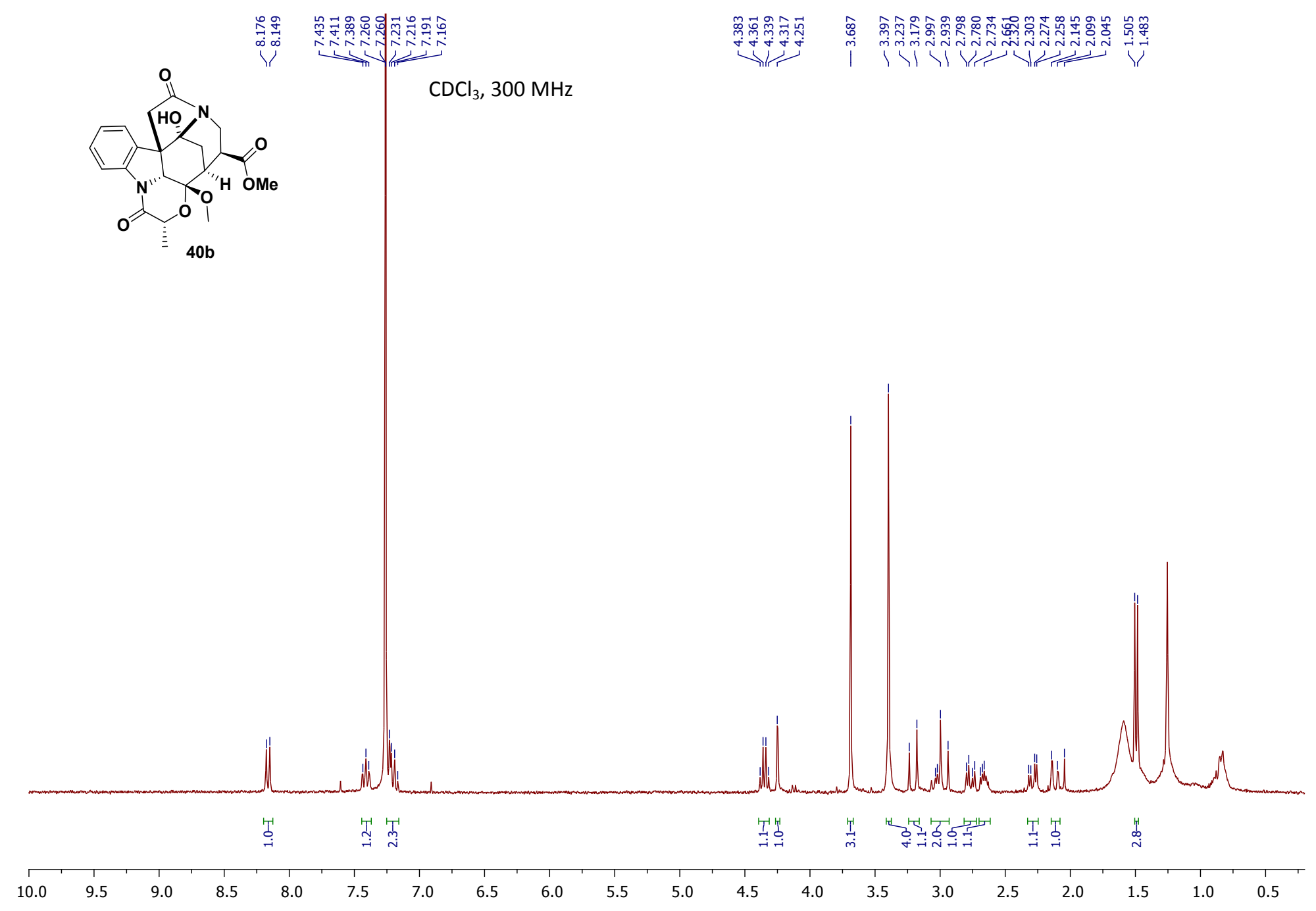




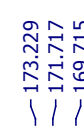

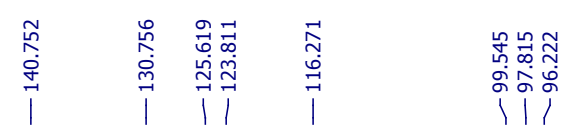

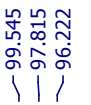

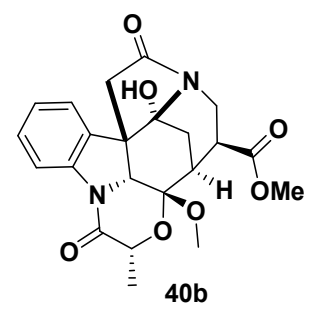

$\mathrm{CDCl}_{3}, 150 \mathrm{~Hz}$
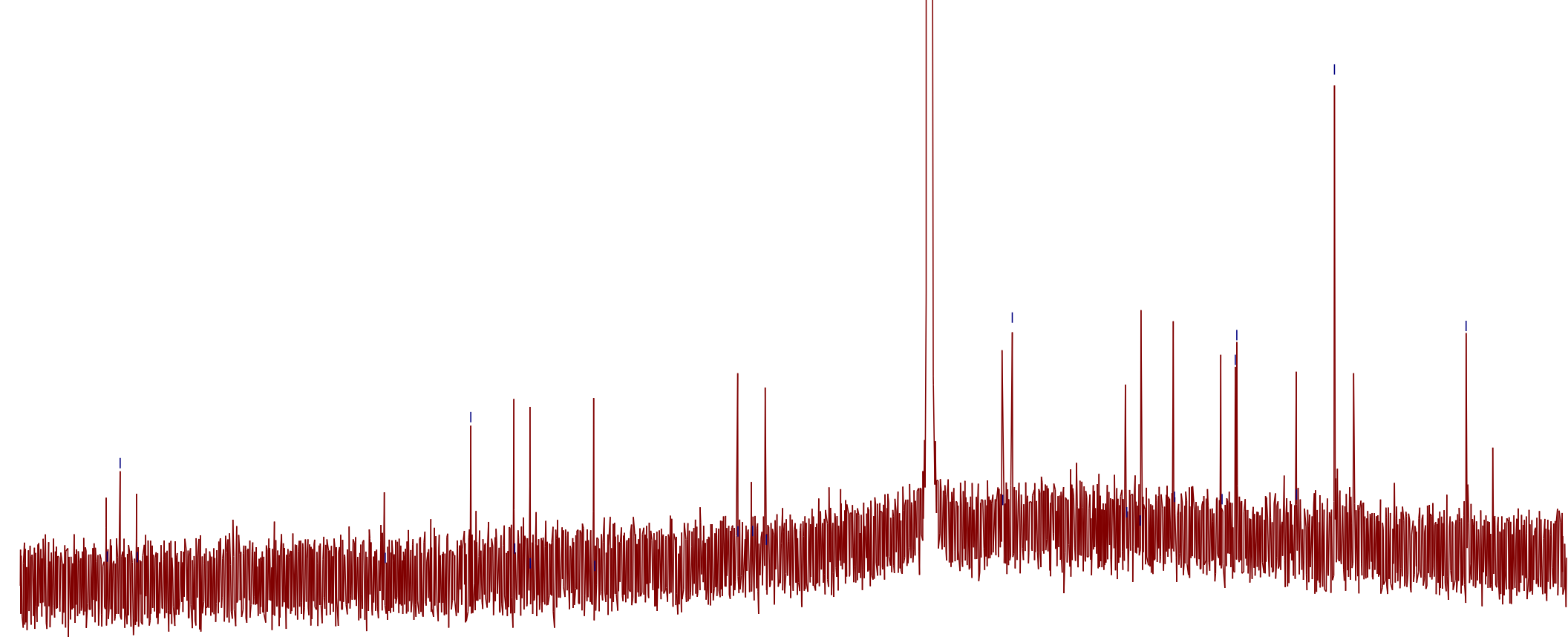
NOE ${ }^{1} \mathrm{H}-{ }^{1} \mathrm{H}$ Peak at $3.69 \mathrm{ppm}$ :

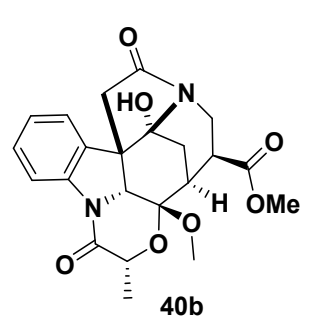

$\mathrm{CDCl}_{3}, 600 \mathrm{MHz}$

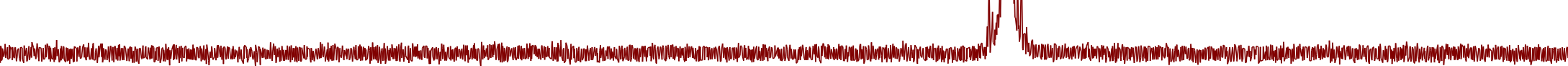

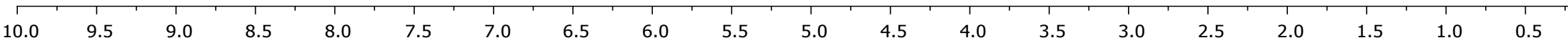



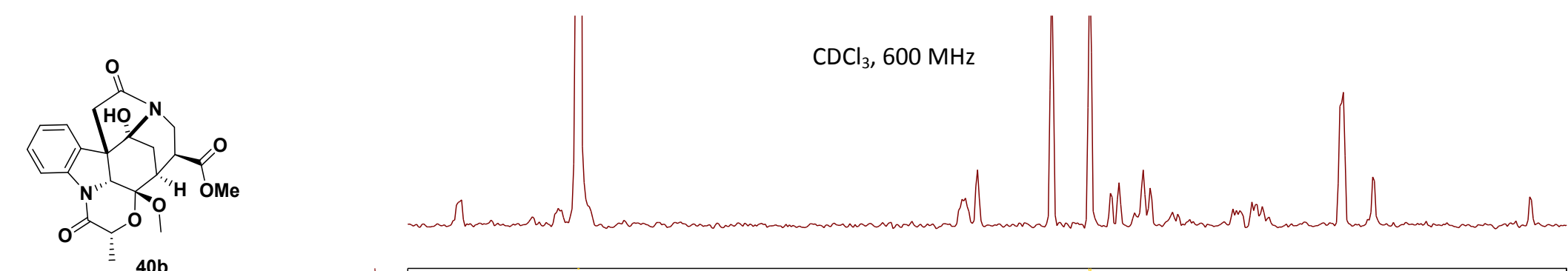

$\cos { }^{1} \mathrm{H}^{-1} \mathrm{H}$ :

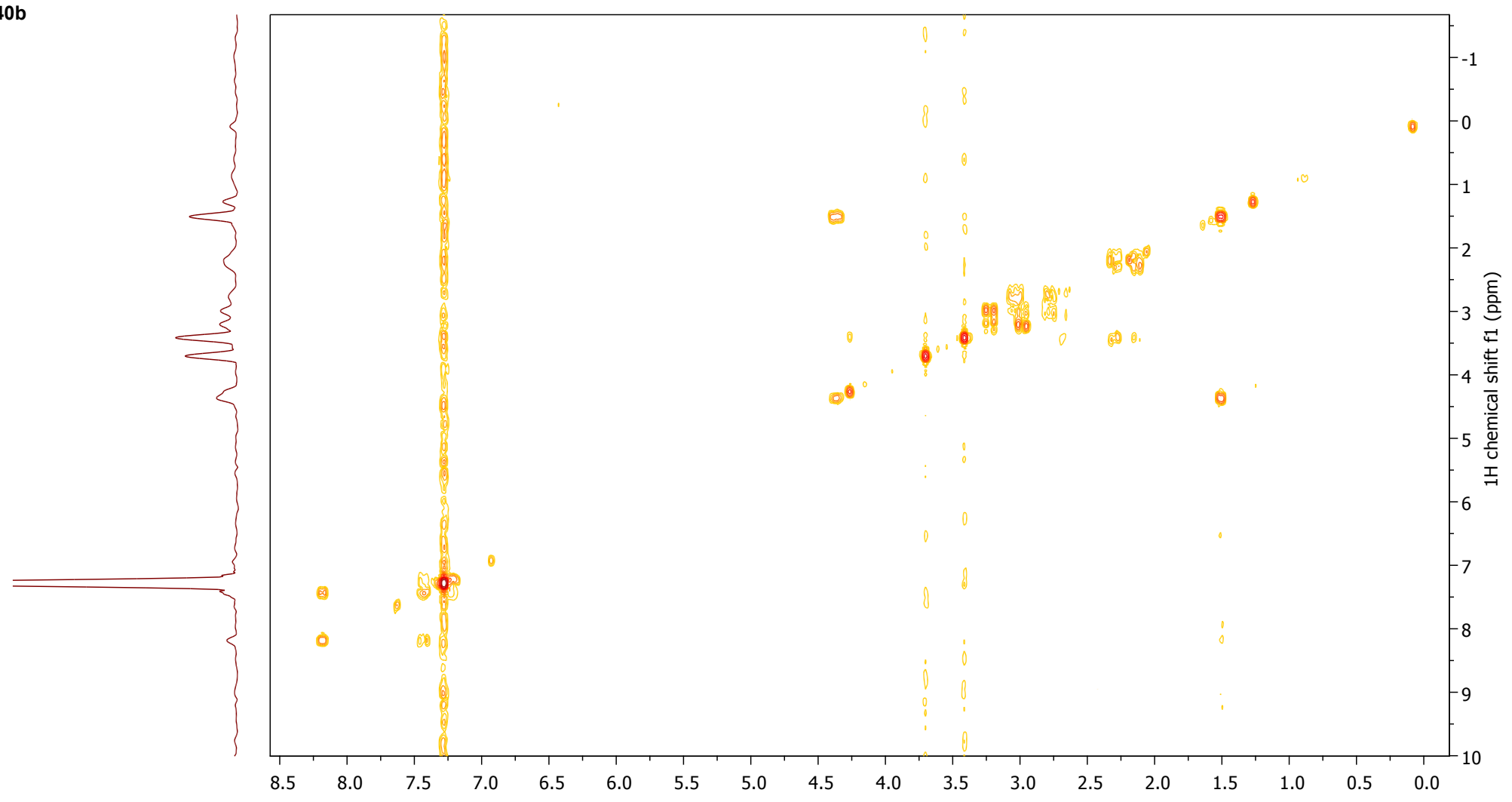




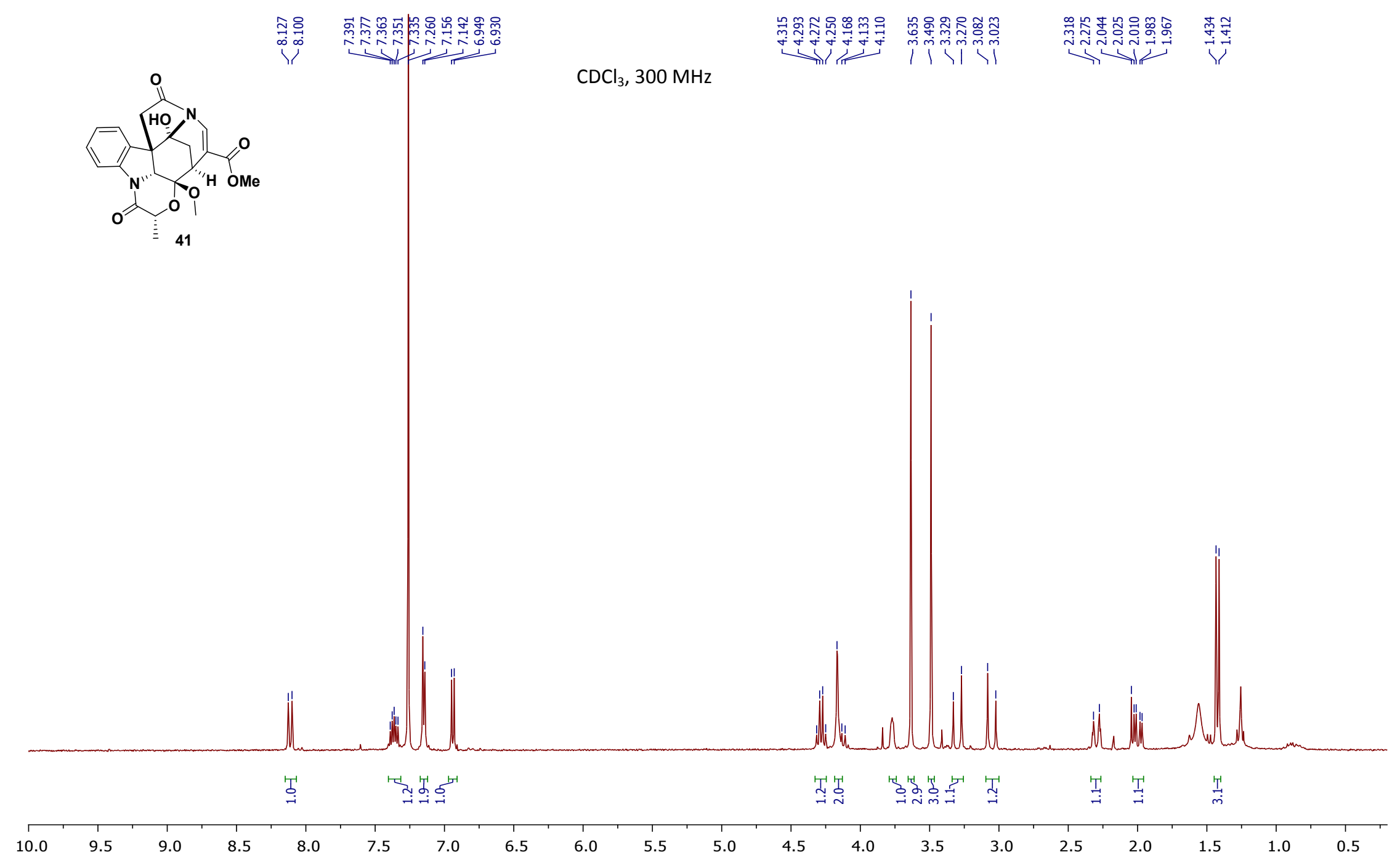



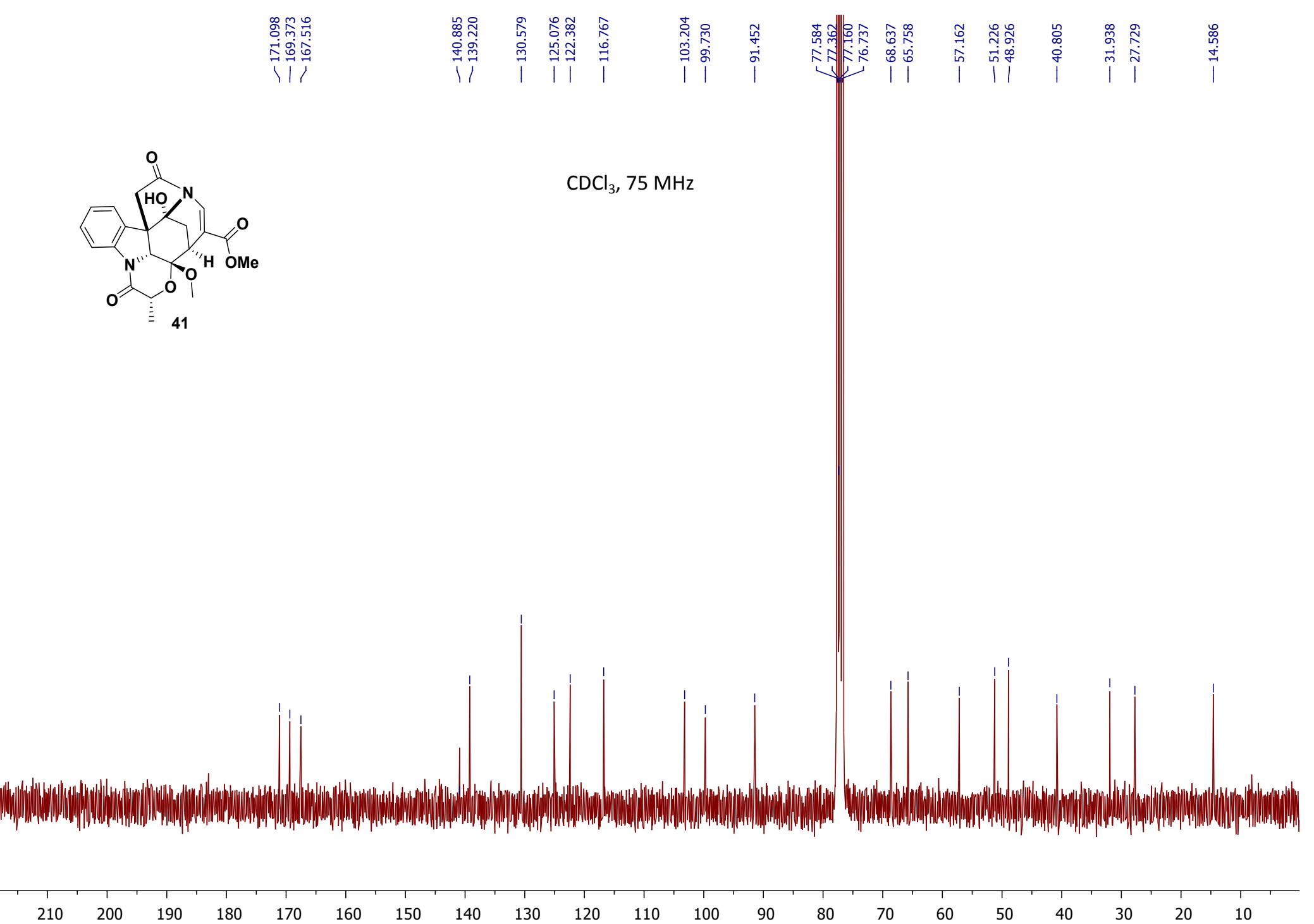
NOE ${ }^{1} \mathrm{H}-{ }^{1} \mathrm{H}$ Peak at $3.63 \mathrm{ppm}$ :

$\mathrm{CDCl}_{3}, 600 \mathrm{MHz}$

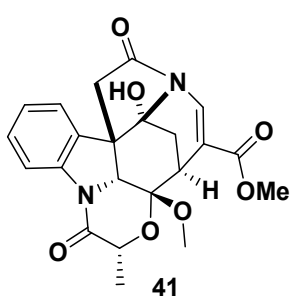

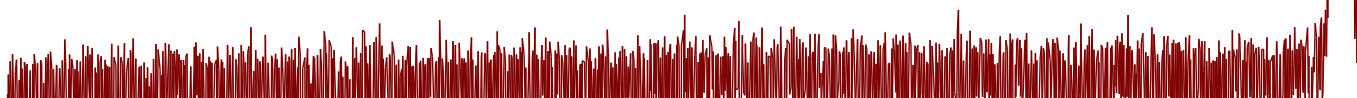

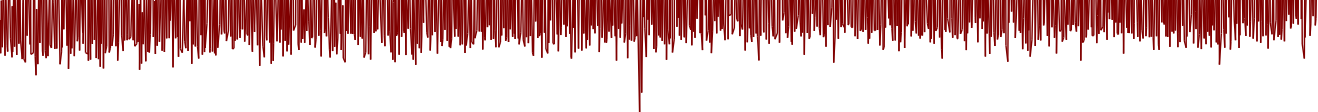

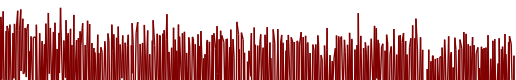

济"

$\begin{array}{ll}7.5 & 7.0\end{array}$

$\begin{array}{ll}6.5 & 6.0\end{array}$

$5.5 \quad 5.0$

4.5

$4.0 \quad 3.5$ 

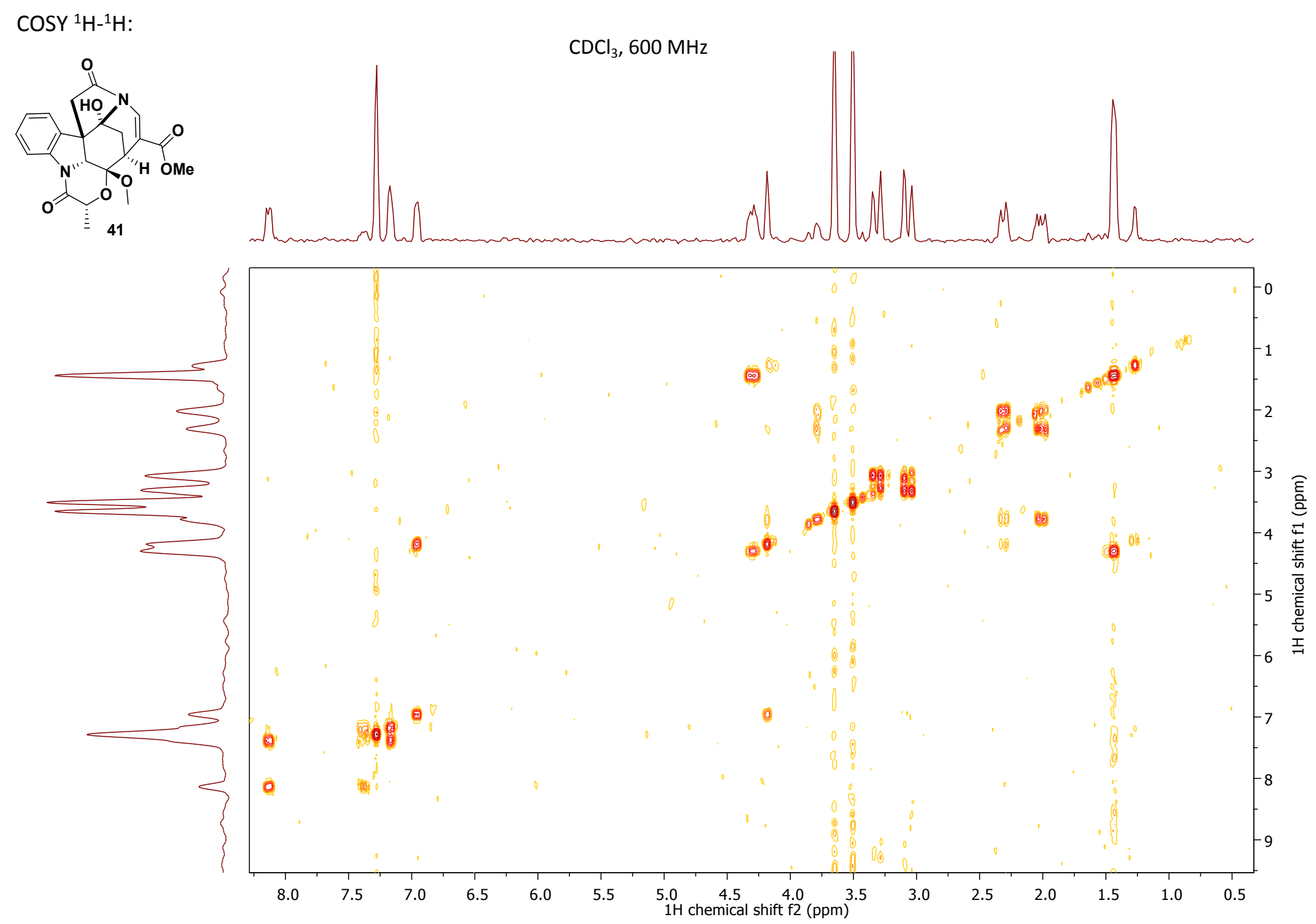


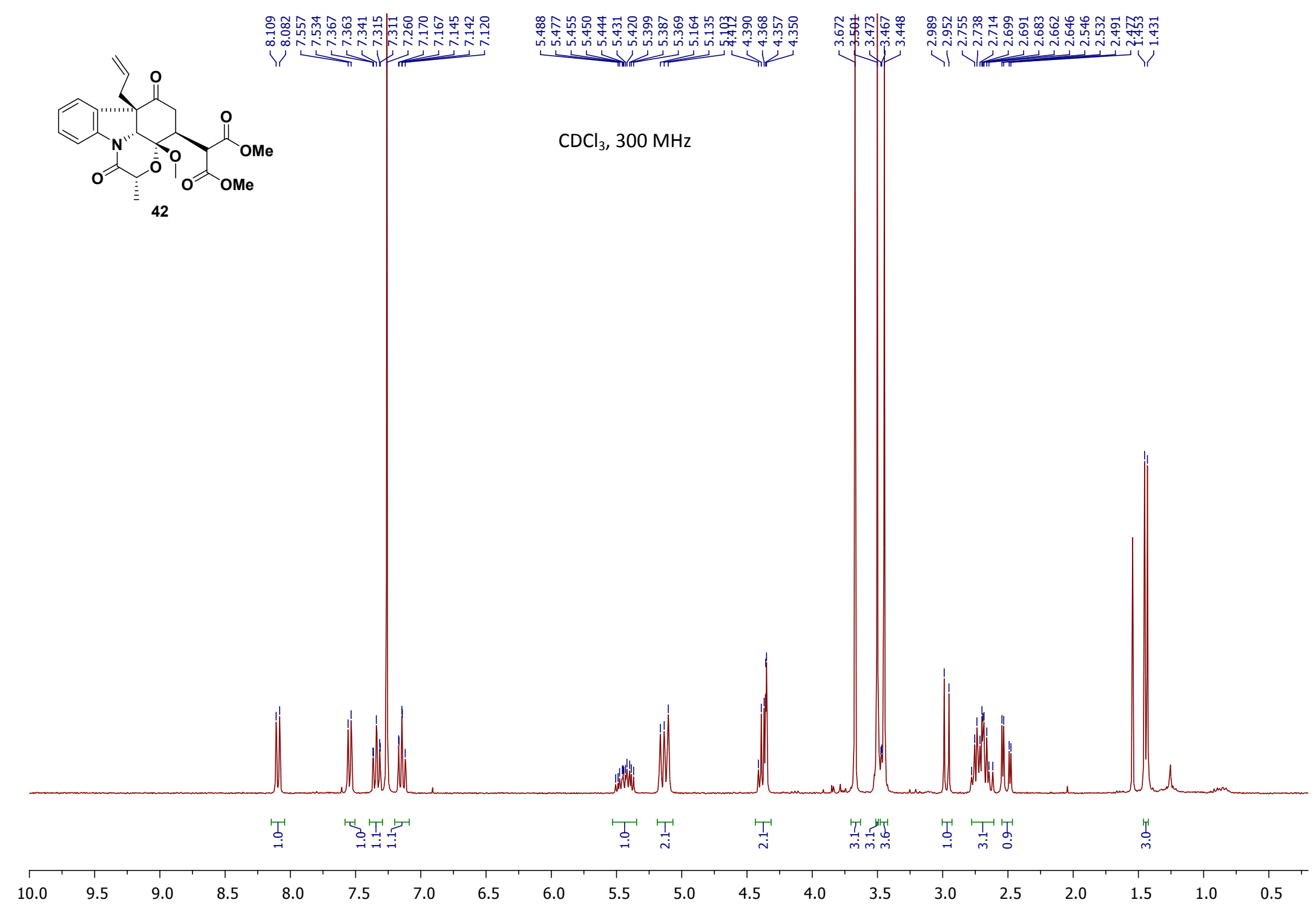




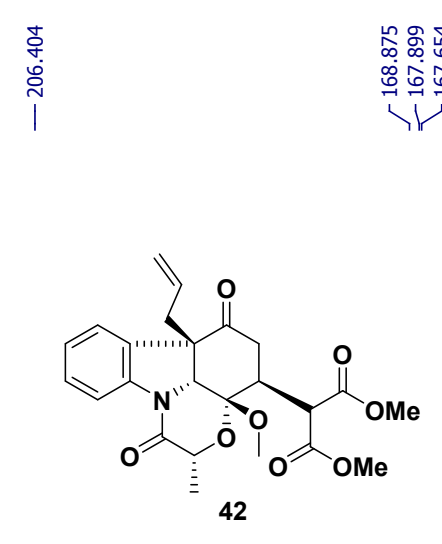

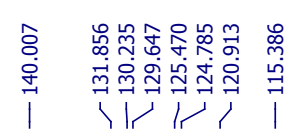

$\mathrm{CDCl}_{3}, 75 \mathrm{MHz}$

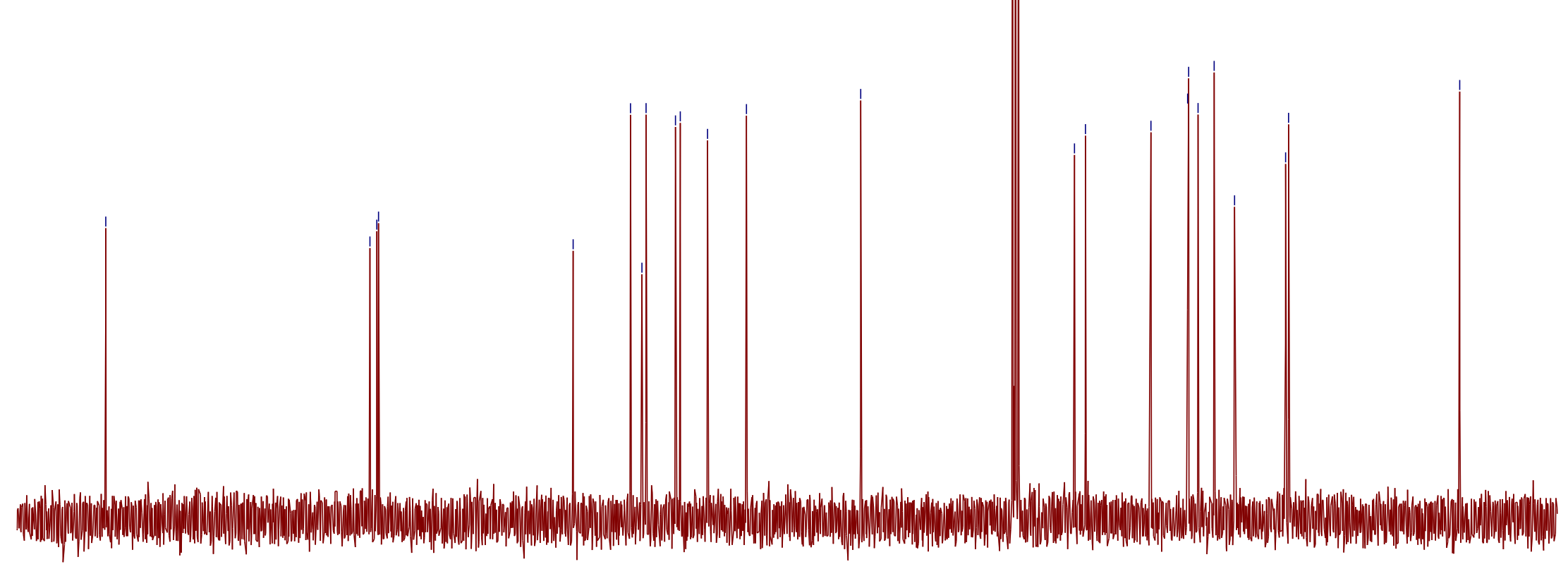

$210 \quad 200$

$190 \quad 180$

$170 \quad 160$

140

120

100

$90 \quad 80$

70

60

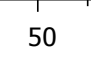

40

20

10 


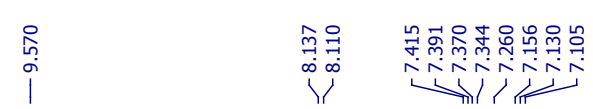

$\mathrm{CDCl}_{3}, 300 \mathrm{~Hz}$
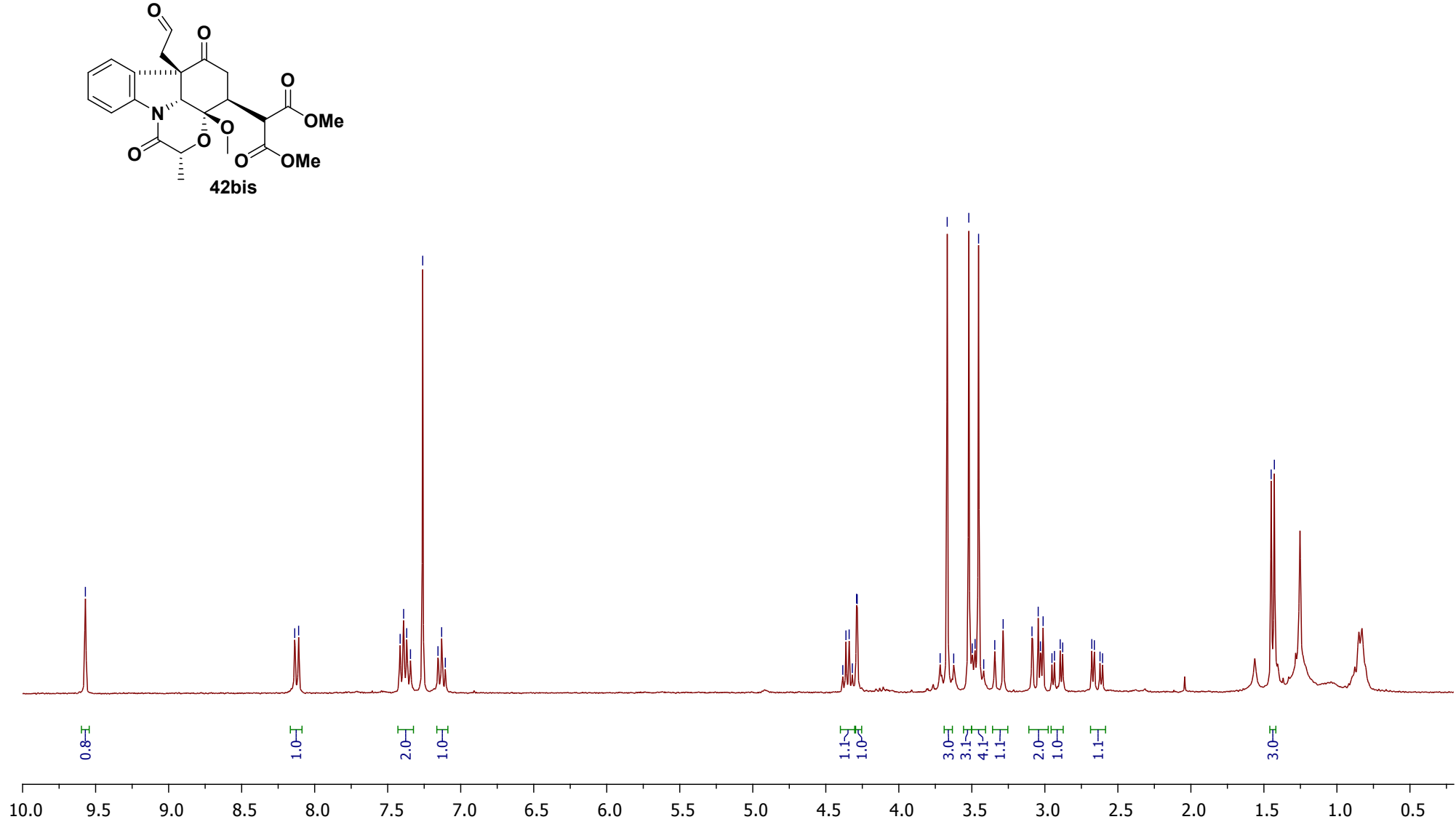

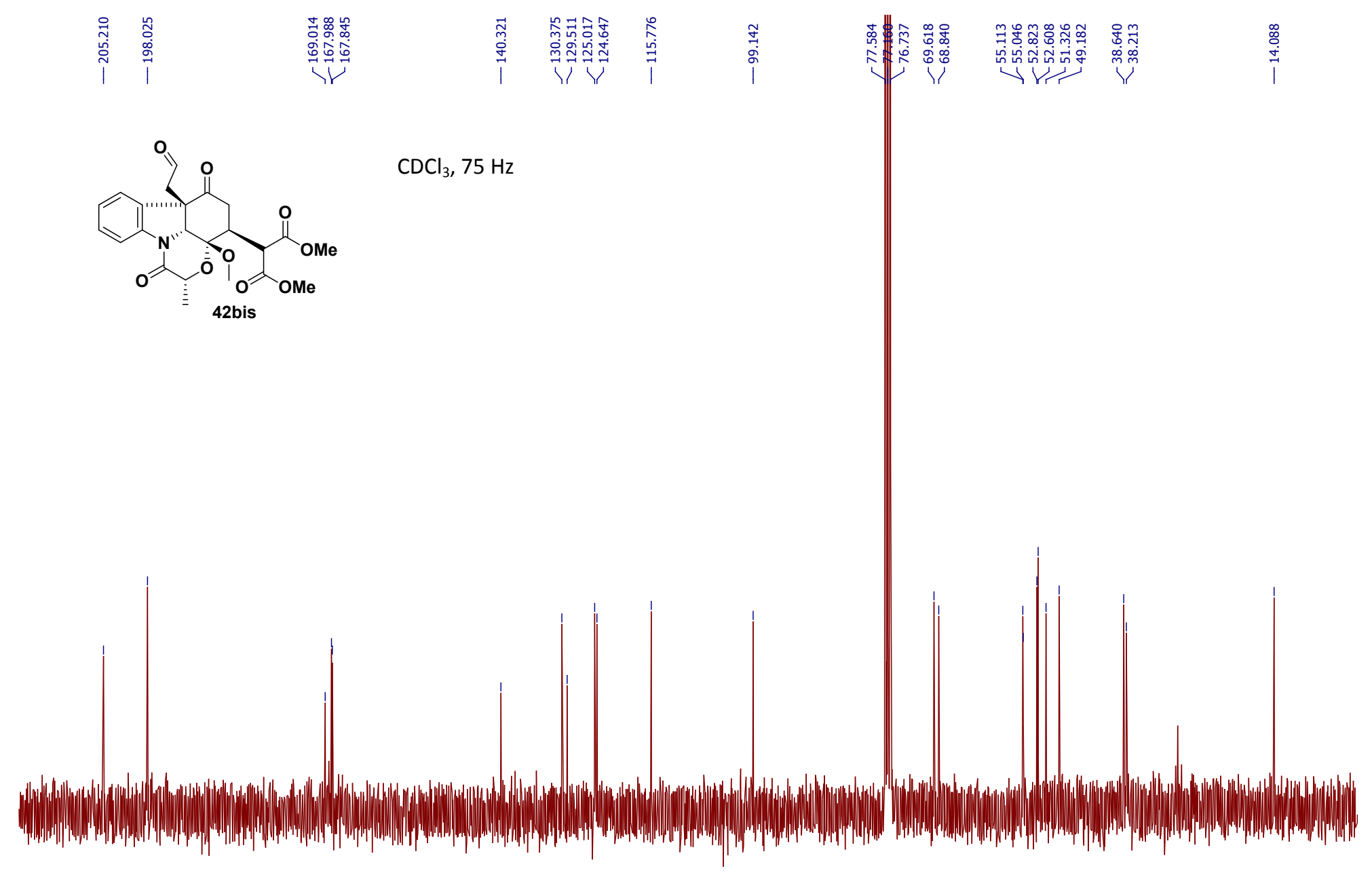


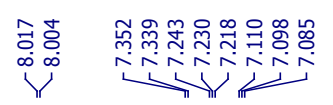

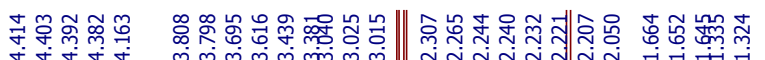

Acetone, $300 \mathrm{MHz}$

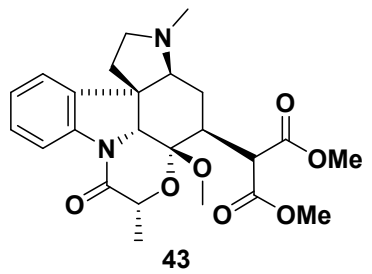

ن

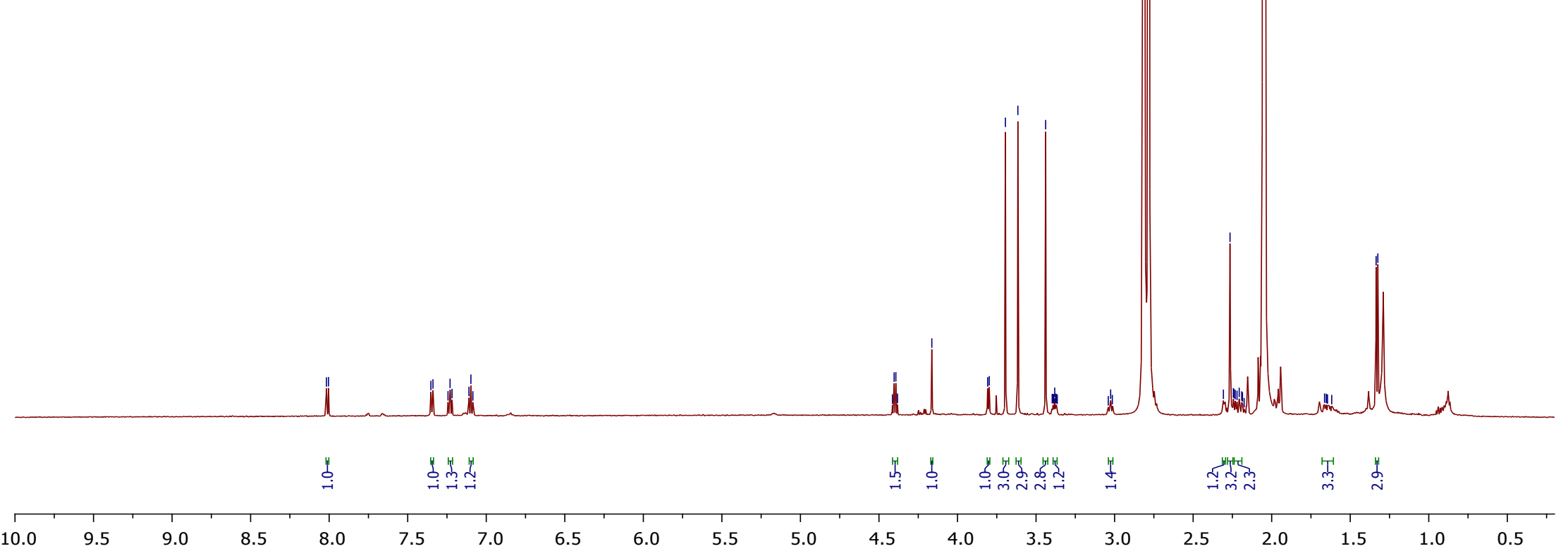




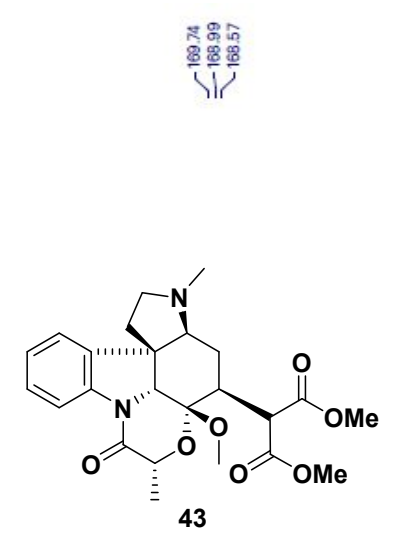

Acetone, $75 \mathrm{MHz}$
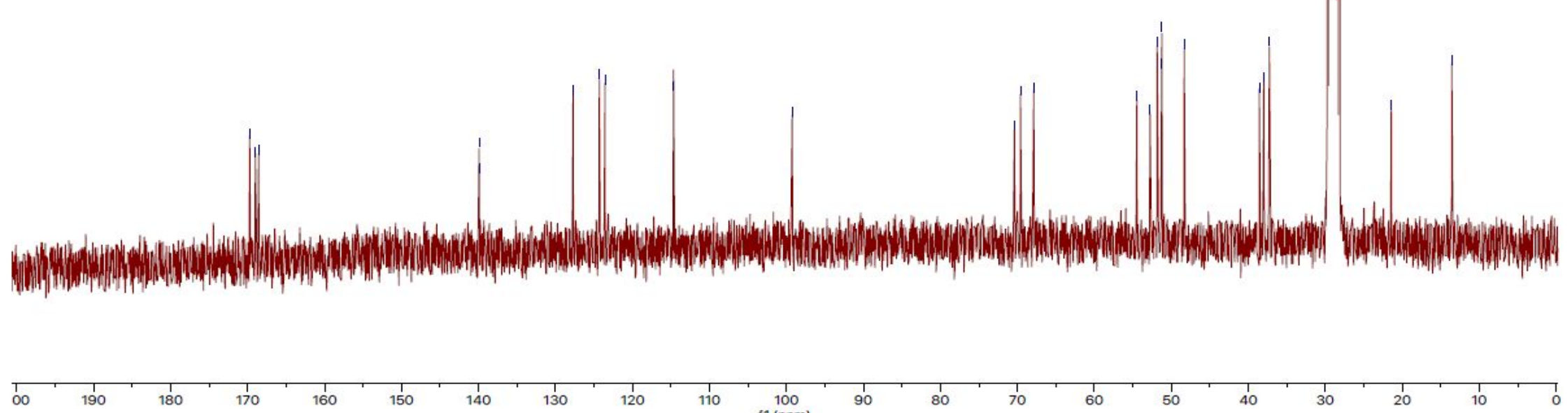

150

140

130

${ }_{120}^{1}$

110

100
$\mathrm{f} 1(\mathrm{pom})$

90

80

60

50

20 